Received 00th January 20xx, Accepted 00th January 20xx

DOI: $10.1039 / x 0 x x 00000 x$

\section{Organo-Catalyzed/Initiated Ring Opening Co-Polymerization of Cyclic Anhydrides and Epoxides: an Emerging Story}

Dmytro Ryzhakov, ${ }^{[a]}$ Gaël Printz, ${ }^{[b]}$ Béatrice Jacques, ${ }^{[b]}$ Samir Messaoudi, ${ }^{[a]}$ Françoise Dumas, ${ }^{[a]}$ Samuel Dagorne* ${ }^{[b]}$ and Franck Le Bideau* ${ }^{[a]}$

Polyesters are omnipresent in our everyday lives and their synthesis via eco-friendly methods is becoming a major challenge today. The co-polymerization of cyclic anhydrides and epoxides was first reported by Fischer in 1960 involving a tertiary amine as an initiator. Since then, metal complexes were used as catalysts in this process, Inoue being a major contributor in this area until Coates' breakthrough using a zinc-based catalyst leading to high molecular weight polymers. Such a pathway to polyesters is the most promising method for accessing a large array of polyesters given the large pool of commercially available or easily synthesizable epoxides and cyclic anhydrides. To date, the use of metal-free organocatalysts/initiators in this co-polymerization remains to be explored: the area is still in its infancy but interesting developments have been reported over the past five years. In this review, we provide a complete overview of such organo-catalyzed/initiated process since 2015.

\footnotetext{
a. Université Paris-Saclay, CNRS, BioCIS, 92290, Châtenay-Malabry, France. E-mail:

franck.lebideau@universite-paris-saclay.fr
}

${ }^{b .}$ Institut de Chimie, CNRS - Strasbourg University, Strasbourg, France 


\section{Introduction}

Because of their facile hydrolytic degradation to benign products, ${ }^{1}$ general biocompatibility and numerous renewable sources, ${ }^{2}$ polyesters appear as candidates of choice for the discovery of new eco-friendly materials. Three routes have been followed (Scheme 1) for their synthesis to date: i) stepgrowth polymerization (SGP) of diols with diacids, ${ }^{3}$ ii) ring opening polymerization (ROP) of cyclic esters ${ }^{4}$ and iii) ring opening co-polymerization (ROCOP) of cyclic anhydrides and epoxides. ${ }^{5}$ The first method, SPG, suffers from high energy costs and requires removal of the resulting water for achieving high molecular weight materials. The second approach, though convenient for an effective and controlled ROP process, is limited by the availability of cyclic ester monomers.

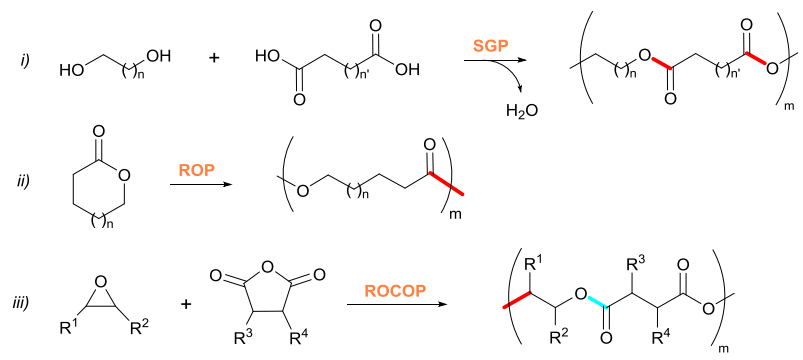

Scheme 1. The three main routes to polyesters. i) the step growth polymerization, ii) the ring opening polymerization and iii) the ring opening co-polymerization of cyclic anhydrides and epoxides

The third pathway, first reported in the sixties by Fischer via the use of a tertiary amine as a polymerization initiator, ${ }^{6}$ is the most promising method for accessing a large array of polyesters related to the possible combination of numerous commercially available or easily synthesizable epoxides and cyclic anhydrides. Four years later, Inoue et al. described ${ }^{7}$ metal-catalyzed $\left(\mathrm{ZnEt}_{2}, \mathrm{MgEt}_{2}, \mathrm{EtMgBr}, \mathrm{CdEt}_{2}\right.$ or $n$-BuLi) ROCOP of epoxides and cyclic anhydrides. This transformation has nevertheless been essentially unexplored until Coates' major breakthrough on a discrete zinc-based catalyst mediating epoxide/anhydride ROCOP to afford high molecular weight polymers. ${ }^{8}$ Since then, most studies have been devoted to metal-based catalysis in this Fischer-InoueCoates reaction. A major drawback of metal-based polymerization catalysis is however the use of rare and/or expensive ${ }^{9}$ and/or toxic ${ }^{10}$ metal catalysts (such as $\mathrm{Sn}, \mathrm{Al}^{11}{ }^{11} \mathrm{Y}$, $\mathrm{Sm}, \mathrm{Lu}$ ), which severely limits their applications particularly in the fields of food packaging and medicine. For instance, the current industrially used lactide ROP catalyst is Sn(octanoate) ${ }_{2}$, whose toxicity is well established. ${ }^{12}$

The term organocatalysis was defined for the first time in 2000 by Mc Millan et al. $^{13}$ and the associated field of research has since then strongly developed. It corresponds to the use of small organic molecules to catalyze chemical reactions and became the third branch of catalysis alongside enzymatic and metal catalysis.

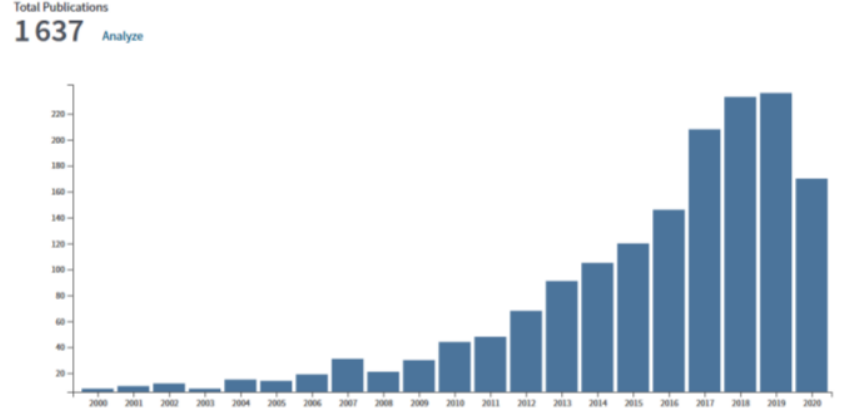

Figure 1. Number of publications on the organocatalyzed polymerization topic since 2004. Generated using Data in Clarivate's Web of Science (C) (September 2020) Platform belonging to Clarivate PLC and/or its Affiliates, using the keywords "organocatalytic polymerization", or "metal-free polymerization

Organocatalysis provides various advantages including i) a larger availability of catalysts at lower costs, ii) a lower sensitivity toward moisture and oxygen, iii) a potentially more eco-friendly and less toxic alternative to metals and iv) the existence of a large chiral pool of organics for enantioselective developments. Organocatalysis has only recently attracted significant interest in polymerization chemistry, ${ }^{14}$ as evidenced by the number of articles published in the last decades on the subject (Figure 1) even though the use of small organic compounds as catalysts in this field has been known for a long time. Indeed, as early as in 1940, Flory reported that low molecular weight polyesters could be prepared from decamethylene glycol and adipic acid using $p$ toluenesulfonic acid as a catalyst. ${ }^{15}$ Figure 1 also shows the number of publications (still limited) per year in this field with a sharp increase since the beginning of the 21st century, thus highlighting the growing importance of this topic.

Although Coates' approach led to significant advances using metal catalysts since 2007,8 only a few developments in the field of organocatalysis have been reported to date on epoxide/anhydride ROCOP. ${ }^{16}$ In contrast, access to polyesters through the organocatalyzed homopolymerization of lactones has been a significantly more studied reaction and numerous organocatalytic systems for the controlled ROP of lactones are now well-established, as discussed hereafter. In the area, Hedrick et al. firstly reported organocatalytic systems associating alcohol initiators and 4dimethylaminopyridine (DMAP) or 4-pyrrolidinopyridine (PPY) as catalysts, for the ROPs of lactides (LA) to access welldefined polylactides (Figure 2). ${ }^{17}$ Since then, they and the group of Waymouth were the most important contributors in design of organocatalysts for the ROP of lactones. In particular, they reported that phosphines were less efficient in the same transformation requiring higher temperatures to achieve high monomer conversions. ${ }^{18}$ Due to their strong nucleophilic character, $\mathrm{N}$-heterocyclic carbenes (NHCs) like imidazole-2-ylidene (IMes) were shown to be highly effective catalysts for the ROP of lactides, $\beta$-butyrolactone, $\delta$ valerolactone $(\delta-\mathrm{VL})$ and $\varepsilon$-caprolactone $(\varepsilon-\mathrm{CL})$ even when generated in situ from the corresponding azolium salts. ${ }^{19}$ Racemic Takemoto's catalyst as well as other bifunctional thiourea analogues, associated or not with amines ((-)sparteine, 1,4-diazabicyclo[2.2.2] octane (DABCO), $N, N, N^{\prime}, N^{\prime}$ - 
tetramethyl-trans-1,2-diaminocyclohexane (TMCHD), 1,8 diazabicyclo[5.4.0] undec-7-ene (DBU), 1,5,7triazabicyclo[4.4.0]dec-5-ene (TBD), N-methylated TBD (MTBD) may also mediate the ROP of lactones through hydrogen bonding activation of the monomer. ${ }^{20} \beta$ Isocupreidine (B-ICD), cupreidine (CPD) and the corresponding thiourea derivatives were successfully used in enantioselective (kinetic resolution) polymerization of rac-LA leading to the production of highly isotactic PLA. ${ }^{21}$

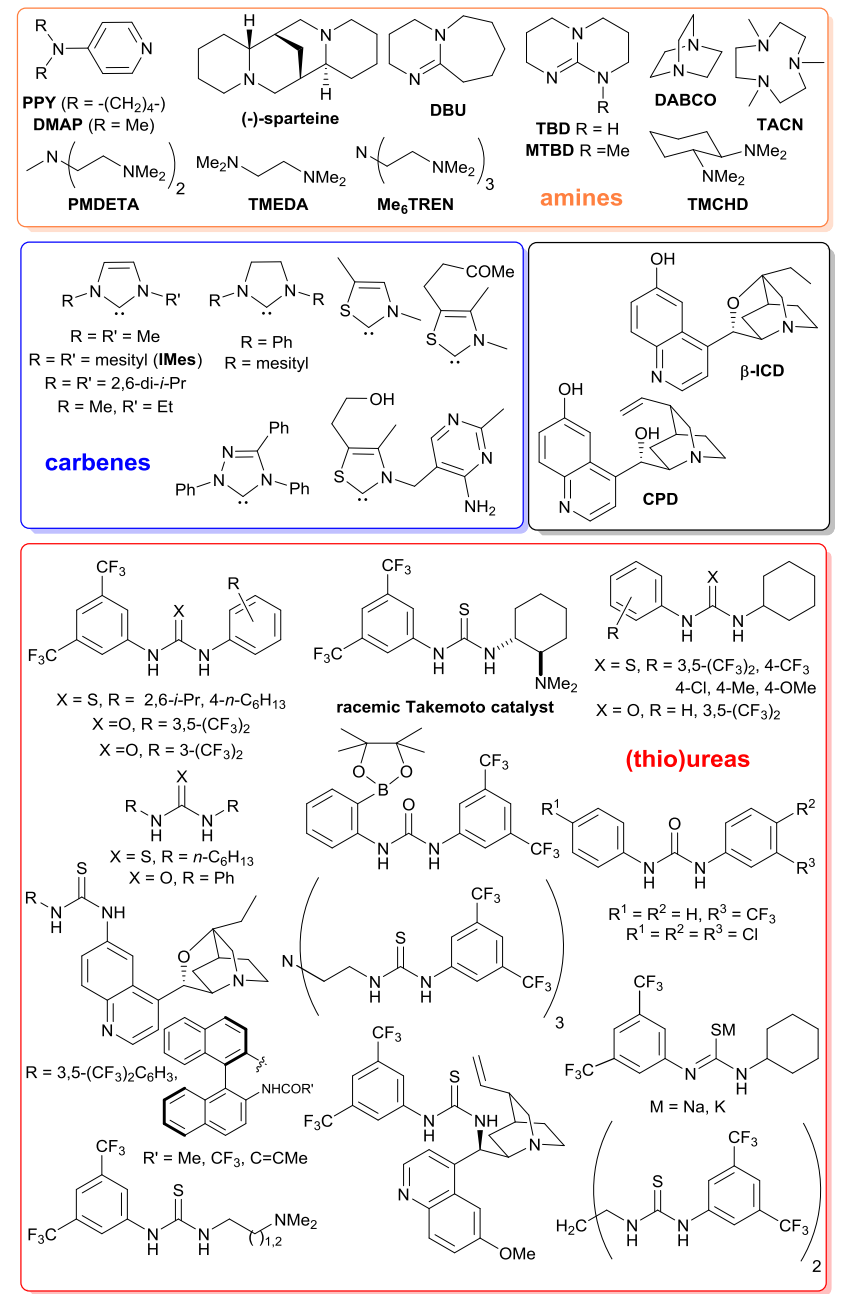

Figure 2. Amines, carbenes and (thio)ureas reported as efficient organocatalysts/initiators in the ROP of lactones.

Ureas, which are less reactive than their thio-analogues, were also used as noncovalent hydrogen bonding catalysts for the ROP of lactones, enhancing their efficiency via deprotonation or through the presence of electronwithdrawing substituents. ${ }^{22}$ The commercially available guanidine TBD also acts as a very active bifunctional catalyst in the ROP of L-lactide (LLA), $\delta$-VL and $\varepsilon-C L{ }^{23}$

Squaramides constitute another type of bifunctional catalysts developed in the field of ROP of lactides (Figure 3) and also operate via noncovalent hydrogen bonding catalysts. $^{24}$ Fluorinated alcohols, ${ }^{25}$ phenols $^{26}$ or (thio)amides ${ }^{27}$ combined to amines appeared as efficient catalytic systems in the ROP of lactones. Phosphazenes such as 2-tert-butylimino-2-diethylamino-1,3-dimethylperhydro1,3,2-diazaphosphorine (BEMP) and $N^{\prime}$-tert-butyl-
$N, N, N^{\prime}, N^{\prime}, N^{\prime \prime}, N^{\prime \prime}$-hexamethylphosphorimidic triamide $(t$ BuP $_{1}$ ) were also reported to promote the ROP of lactones. ${ }^{28}$ Less sophisticated compounds such as methane sulfonic acid or trifluoromethanesulfonic acid catalyze the ROP of lactones, ${ }^{29}$ while diphenyl phosphate in association with various alcohols as initiators is an operative catalyst for the ROP of $\delta$-VL and $\varepsilon-C L{ }^{30}$ Sulfonamides associated with DMAP were used in the ROP of lactides. ${ }^{31}$
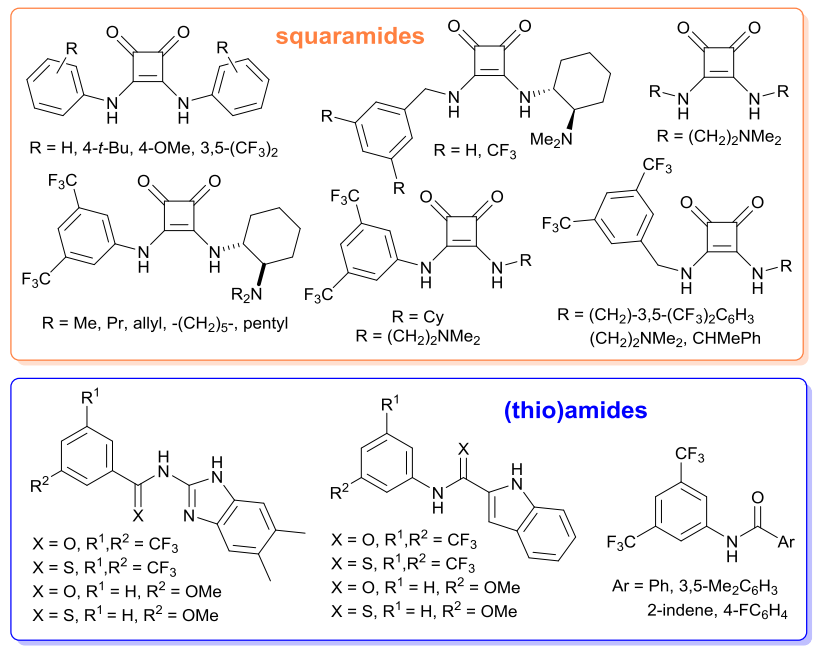

\begin{tabular}{|c|c|c|c|}
\hline $\begin{array}{l}\mathrm{HO}\left(\mathrm{CF}_{3}\right)_{2} \mathrm{C} \\
\mathrm{R}=\mathrm{H} \text {, vinyl, methacryloyl }\end{array}$ & $\begin{array}{l}\mathrm{R}=\mathrm{C}\left(\mathrm{CF}_{3}\right)_{2} \mathrm{OH} \\
\mathrm{R}=\mathrm{Me} \text {, vinyl }\end{array}$ & $\begin{array}{l}\mathrm{F}_{3} \mathrm{C}-{\underset{\mathrm{OH}}{\mathrm{O}}}_{\mathrm{R}}^{\mathrm{R}} \mathrm{CF}_{3} \\
\mathrm{H}, \mathrm{Me}, \mathrm{CF}_{3}\end{array}$ & $\begin{array}{l}\mathrm{R} \\
\mathrm{R}=\mathrm{H}, 2-\mathrm{CF}_{3}, 3-\mathrm{CF}_{3} \\
4-\mathrm{CF}_{3}, 3,5-\left(\mathrm{CF}_{3}\right)_{2} \\
2-\mathrm{OMe}, 3-\mathrm{OMe} \\
4-\mathrm{OMe}, 3,3^{-}-(\mathrm{OMe})_{2}\end{array}$ \\
\hline
\end{tabular}

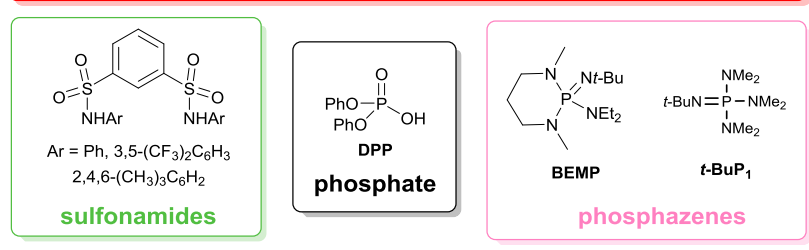

Figure 3. Squaramides, (thio)amides, alcohols, phenols, sulfonamides, phosphate and phosphazenes reported as efficient organocatalysts/initiators in the ROP of lactones

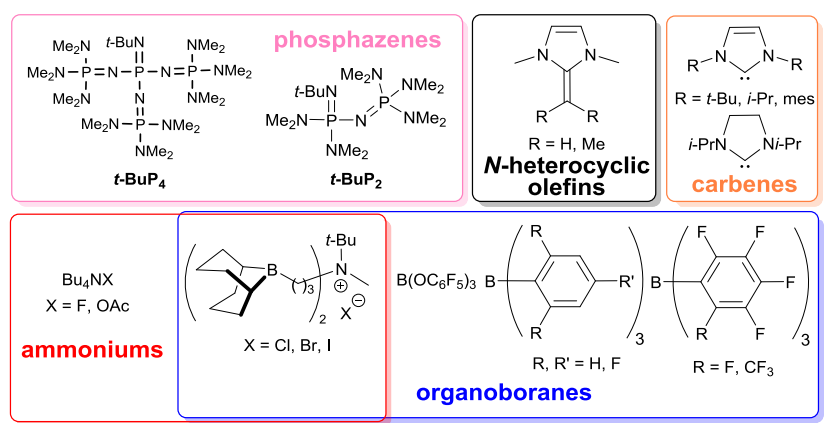

Figure 4. Phosphazenes, $N$-heterocyclic olefins, carbenes, ammoniums and organoboranes reported as efficient organocatalysts/initiators in the homopolymerization of epoxides.

One major side-reaction encountered in the ROCOP of cyclic anhydrides and epoxides is epoxides homopolymerization, a reaction that has been well studied due to its interest for polyether syntheses. Access to such homopolymers primarily relies on the ROP of epoxides, typically involving alkali metals as initiators. ${ }^{32}$ However, a few 
organic compounds were also used as initiators or organocatalysts for epoxide polymerization. ${ }^{33}$ Since the first example in the area in 1996, ${ }^{34}$ phosphazenes (Figure 4) are the most employed organocatalysts (mainly in association with alcohols) for epoxides ROP. ${ }^{35}$ In this series, 1-tert-butyl4,4,4-tris(dimethylamino)-2,2-bis[tris(dimethylamino) phosphoranylidenamino] $-2 \Lambda^{5}, 4 \Lambda^{5}$-catenadi(phosphazene) (t$\mathrm{BuP}_{4}$ ) is most commonly used. Compound $t$-BuP ${ }_{1}$ (Figure 3 ) and 1-tert-butyl-2,2,4,4,4-pentakis(dimethylamino)- $2 \Lambda^{5}, 4 \Lambda^{5}$ catenadi(phosphazene) $\left(t-\mathrm{Bu}-\mathrm{P}_{2}\right)$ as well as amines (DBU or MTBD, Figure 2) were shown to be active in the presence of Lewis acid $\mathrm{Et}_{3} \mathrm{~B} .{ }^{36}$ DMAP (Figure 2), ${ }^{37} \mathrm{~N}$-heterocyclic olefins, ${ }^{38}$ ammoniums, ${ }^{39}$ organoboranes ${ }^{40}$ ammonium functionalyzed boranes, ${ }^{41}$ and $\mathrm{NHCs}^{42}$ are also known to polymerize epoxides in a controlled manner.

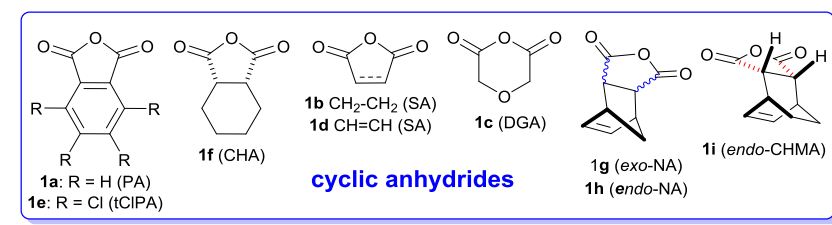

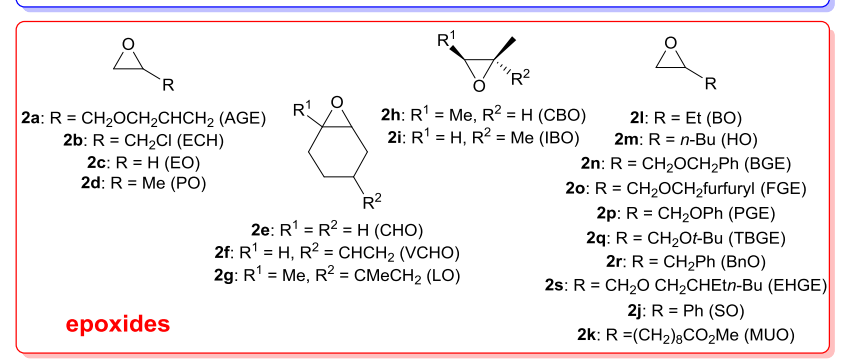

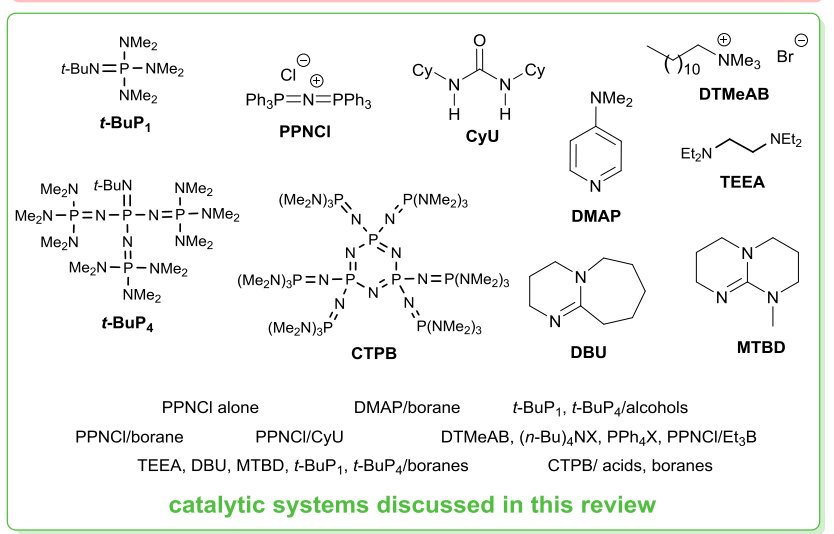

Figure 5. Monomers and organocatalyst/initiator systems for the ROCOP of cyclic anhydrides and epoxides.

Figure 5 shows the monomers and organocatalytic/initiator systems for the ROCOP of cyclic anhydrides and epoxides discussed in this review.

After a presentation of the Fischer-Inoue-Coates copolymerization from its discovery in 1960 to its revival in 2007, the present review will summarize and discuss the ROCOP of epoxides and anhydrides initiated and/or catalyzed by organic molecules since 2015 . We believe that such a subject, still in its infancy, deserves a great deal of attention because of the advances it could bring in the field of polymer chemistry, through the large diversity of materials that may be produced using eco-friendly/-compatible chemistry.

\section{The Fischer-Inoue-Coates co-polymerization, origin and revival}

In $1960,{ }^{6}$ Fischer showed that phthalic anhydride 1a and allyl glycidyl ether (AGE) $\mathbf{2 a}$ or epichlorohydrin $\mathbf{2} \mathbf{b}$ reacted, in the presence of dimethylbenzylamine at $70-200^{\circ} \mathrm{C}$ for $2-53 \mathrm{~h}$, to give linear polyesters with molecular numbers ranging from 2.5 to $18.4 \mathrm{kDa}$ (Scheme 2).

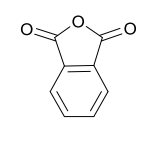

1a

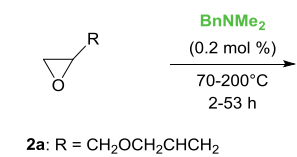

2b: $\mathrm{R}=\mathrm{CH}_{2} \mathrm{Cl}$

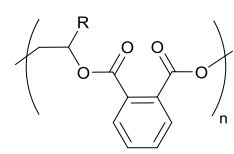

$2.4<M_{\mathrm{n}}<18.4 \mathrm{kDa}$
Scheme 2. The first reported ring opening co-polymerization of cyclic anhydride and epoxides by Fischer.

When prepared from commercial reactants, molecular weights ranged from 2.4 to $4.0 \mathrm{kDa}$. Distillation of the starting epoxide gave products ranging from 6.0 to $8.0 \mathrm{kDa}$ while a thorough purification of the epoxide as well as an exclusion of water raised these values to the 10.0-12.0 $\mathrm{kDa}$ level. In one case (phthalic anhydride + epichlorohydrin), $M_{\mathrm{n}}$ value of $18.4 \mathrm{kDa}$ was reached. When equimolar proportions of monomers were used, less than $1 \%$ homopolymerization or other side reactions were observed, indicating a high selectivity in ester linkage. This was not the case for other epoxides derived from vinylcyclohexene, cyclohexene or stearates, which led up to $40 \%$ homopolymerization of the epoxide monomer.

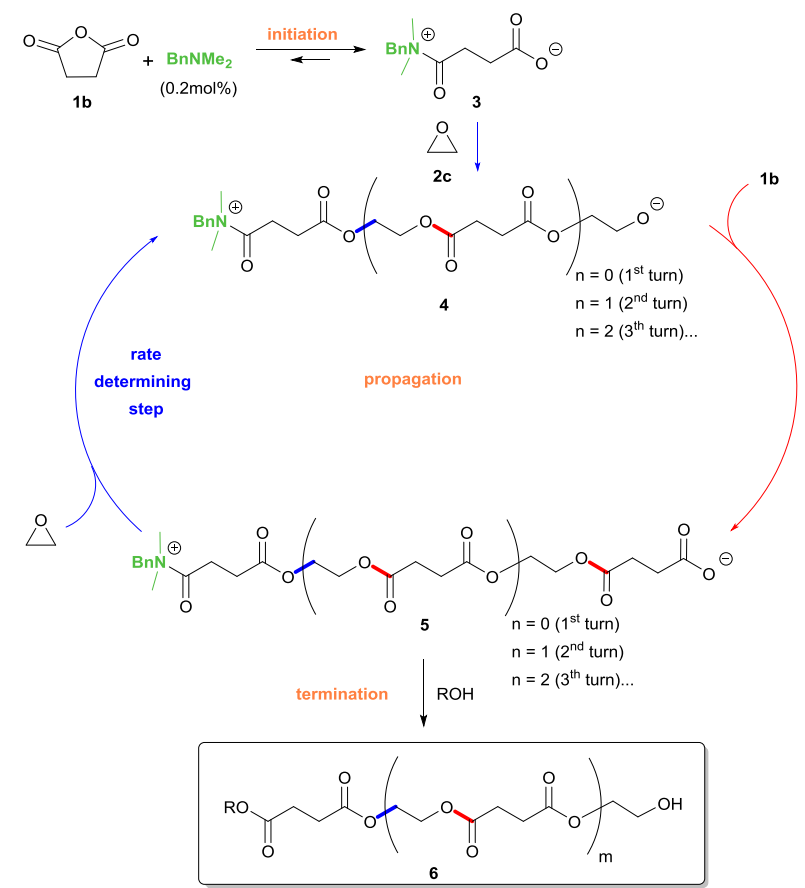

Scheme 3. A reasonable mechanism for the ROCOP of cyclic anhydrides and epoxides proposed by Fischer.

A mechanism was proposed by Fischer for this copolymerization (Scheme 3) whose initiation step is the activation of the anhydride $\mathbf{1} \mathbf{b}$ by $\mathrm{BnNMe}_{2}$. Owing to the large excess of the former over the initiator, the equilibrium is strongly shifted in favour of the ring-opened zwitterion $\mathbf{3}$, deactivating the amine and subsequent epoxide 
homopolymerization. Carboxylate $\mathbf{3}$ next reacts with epoxide 2c providing compound $\mathbf{4}(n=0)$ as the first compound of the propagation cycle, which delivers $\mathbf{5}$ in the presence of anhydride $\mathbf{1 b}$. Compound $\mathbf{5}(\mathrm{n}=0)$ then adds to one molecule of epoxide $\mathbf{2 c}$ in the rate determining step to afford $4(n=1)$ and continuation of these alternating steps produces polyester $\mathbf{6}$ after termination due to alcohol or water traces actions.

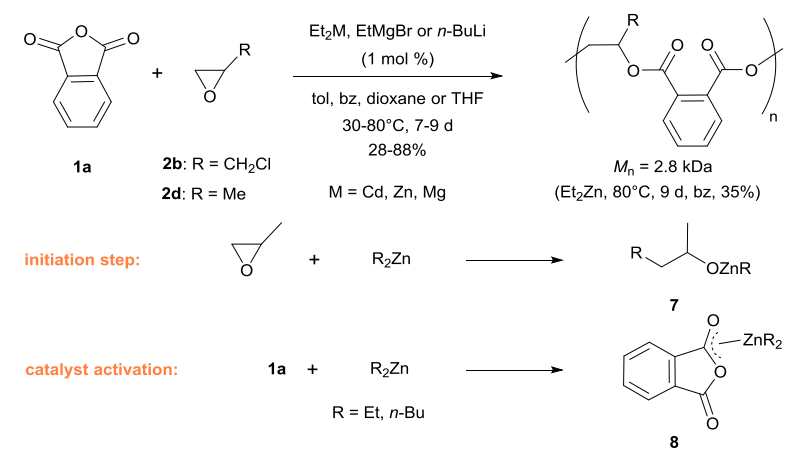

Scheme 4. First example of metal-initiated ROCOP of cyclic anhydride and epoxides reported by Inoue et al..

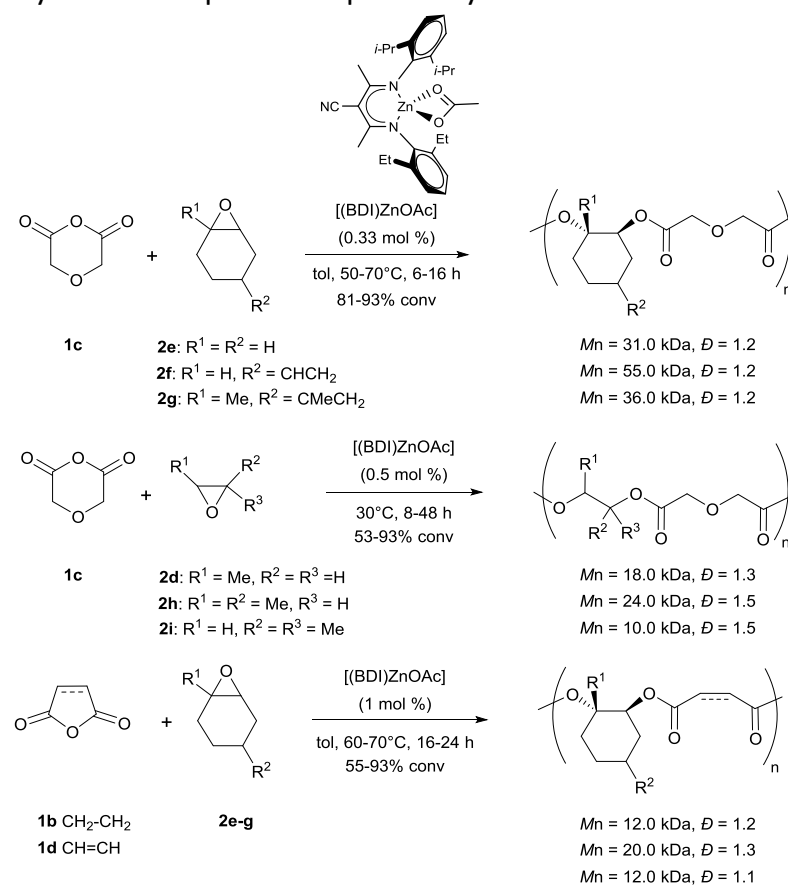

Scheme 5. Coates' breakthrough in the ROCOP of cyclic anhydrides and epoxides with a discrete zinc complex catalyst; first access to high molecular weight polymers.

Four years after Fischer's seminal work, Inoue et al. reported $^{7}$ the first metal-initiated ROCOP of cyclic anhydrides and epoxides. Phthalic anhydride $\mathbf{1 a}$ and epichlorohydrin $\mathbf{2 b}$ or propylene oxide $\mathbf{2 d}$ reacted, in the presence of organometallic compounds ( $\mathrm{ZnEt}_{2}, \mathrm{MgEt}_{2}, \mathrm{EtMgBr}, \mathrm{CdEt}_{2}$ or $n$ BuLi) at $30-80{ }^{\circ} \mathrm{C}$ for $7-9$ days to deliver the corresponding polyesters (Scheme 4 ) in yields ranging from 28 to $88 \%$. In 1969 , when studying the mechanism of this reaction, ${ }^{43}$ they reported a moderate molecular weight of $2.8 \mathrm{kDa}$ for such co-polymer starting from a 1:1 mixture of monomers $1 \mathbf{a}$ and 2d after 9 days at $80^{\circ} \mathrm{C}$ in benzene. Based on experimental evidences and IR spectroscopy, they proposed an initiation step involving addition of the alkyl zinc to the epoxide to afford the alkyl zinc alkoxide 7 , with an activation of the former via its chelation to phthalic anhydride to form complex 8. Chain growth then follows the same alternating pathway as described by Fischer (Scheme 3).

Still starting from phthalic anhydride $1 \mathbf{1 a}$ and propylene oxide $\mathbf{2 d}$, Inoue et al. also described in $1985^{44}$ their alternate co-polymerization using the combination of an $\mathrm{Al}(\mathrm{III})$ porphyrin complex and a quaternary ammonium salt as a catalytic system, leading to polyester materials with very narrow polydispersities $(\Theta=1.1)$ but low molecular weights ranging from 2.3 to $3.0 \mathrm{kDa}$. In 2007, high molecular weight polyesters (10.0-55.0 kDa) through an epoxide/anhydride ROCOP were first reported by Coates et al., using a discrete zinc-based catalyst incorporating a bidentate $\beta$-diketimidato moiety as a supporting ligand (Scheme 5). ${ }^{8}$ Diglycolic anhydride 1c was opposed to six epoxides 2d, 2e-i while succinic and maleic anhydrides $\mathbf{1 b}$ and $\mathbf{1 d}$ were respectively reacted with $\mathbf{2 e - g}$. Polyester copolymers were selectively synthesized under relatively mild conditions $\left(30-70^{\circ} \mathrm{C}, 6-48\right.$ h) with low polydispersity $(1.1<\theta<1.5)$ and high ester linkage content (>95\%). This work marked a turning point in Fischer-Inoue-Coates co-polymerization and led to numerous developments on metal-catalyzed epoxide/anhydride ROCOPs, ${ }^{45}$ contrasting with the only recent revival of organocatalyzed approaches in the area. ${ }^{46}$

\section{Recent organocatalyzed developments in the Fischer-Inoue-Coates co-polymerization}

The influence of the purity of monomers and initiator on the course of the Fischer-Inoue-Coates co-polymerization of phthalic anhydride $\mathbf{1 a}$ and cyclohexene oxide $\mathbf{2 e}$, was studied by Cramail, Hošt'álek and co-workers (Table 1 ). ${ }^{47}$

Table 1. Study of the influence of the purity of phthalic anhydride on the course of the ROCOP with cyclohexene oxide according to Cramail, Hošt'álek and co-workers.

1a pure-
chased in


They first observed that the same experiment, repeated a few years later with the same anhydride 1a purchased in 2013, yielded different results (Table 1 , entry 1 vs 2 ) and particularly a large decrease in molecular weight of the synthesized polyester. The role of Bis(triphenylphosphine)iminium chloride (PPNCl) and epoxide $2 \mathbf{e}$ was ruled out using multiple precipitation and distillation from $\mathrm{CaH}_{2}$ respectively, for their purification. Attention was then focused on the purity of the anhydride $\mathbf{1 a}$ and its potential hydrolysis into the corresponding diacid over time. On the one hand, using a new batch of 1a (Table 1, entry 3 ) and purifying it successively by recrystallization (Table 1 , entry 4 ) and sublimation (Table 1, entry 5) allowed a decrease in the diacid content which led to polyesters with higher molecular weights. Concomitantly, a decrease in polymerization activity was noticed, thus showing the role of diacid as an initiator in the process. On the other hand, adding increasing amounts of phthalic acid induced a reduction in the polyester molar masses (Table 1, entry 6 and 7).

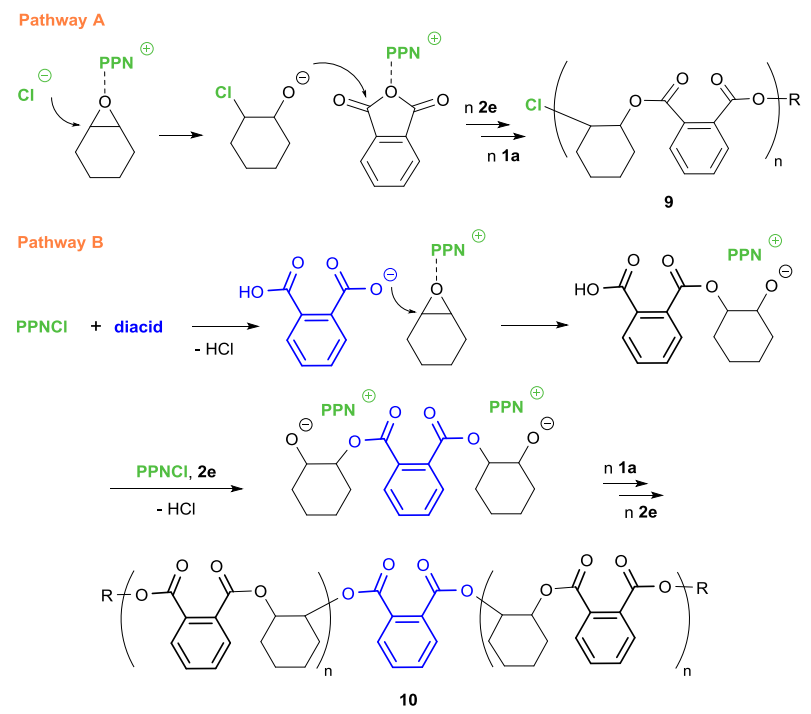

Scheme 6. A reasonable mechanism proposed by Cramail, Hošt'álek and co-workers to explain the structures of the polyesters generated in the ROCOP of phthalic anhydride and epoxide initiated by PPNCI.

Two mechanisms of initiation by PPNCl (Scheme 6, pathway A) and phthalic acid (pathway B) were proposed leading to polyesters 9 and $\mathbf{1 0}$ respectively and explaining the bimodal GPC distribution of the resulting copolymers.

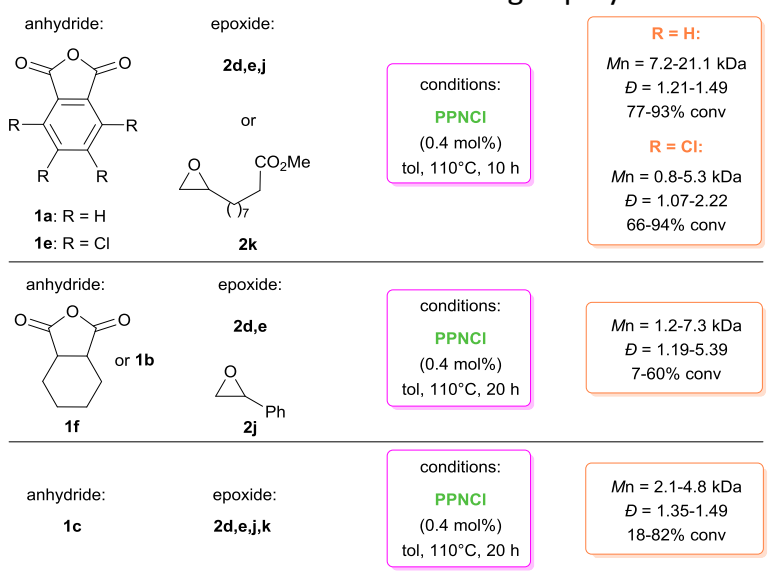

Figure 6. Results of the ROCOP of several cyclic anhydrides and epoxides following the protocol of Cramail, Hošt'álek and coworkers.
PPNCl was replaced by other bases $\left(n-\mathrm{Bu}_{4} \mathrm{Cl}, n-\mathrm{Bu}_{4} \mathrm{Br}\right.$, DMAP, $\mathrm{PPh}_{3}, \mathrm{DABCO}$ and TBD) without improvement of molecular weights or conversion. Several other epoxides and cyclic anhydrides were also tested for ROCOP initiated by PPNCl to explore the versatility of the reaction (Figure 6). Phthalic anhydride $\mathbf{1 a}$, its chlorinated analogue tetrachlorophthalic anhydride 1e, DGA 1c and cyclohexene anhydride 1f were opposed to epoxides $\mathbf{2 d}, \mathbf{e}, \mathbf{j}$ and methylundec-10-enoate oxide (MUO) $\mathbf{2 k}$, which can be produced from renewable castor oil, to deliver the corresponding polyesters displaying a broad range of glass transition temperatures $\left(-29\right.$ to $\left.154^{\circ} \mathrm{C}\right)$ and thermal degradation between 216 and $303^{\circ} \mathrm{C}$. The best results were obtained with phthalic anhydride $\mathbf{1 a}$ and epoxides $\mathbf{2 d , e , j , k}$ with $M_{\mathrm{n}}$ up to $21.1 \mathrm{kDa}, 77-93 \%$ conversion and polydispersities ranging between 1.21 and 1.49. The copolymerization of other cyclic anhydrides yielded polyesters with shorter chain length (0.8-7.3 kDa) and lower conversions even after longer reaction time $(20 \mathrm{~h})$. The co-polymerization of maleic anhydride $\mathbf{1 d}$ with $\mathbf{2} \mathbf{d}$ or $\mathbf{2 e}$ afforded insoluble dark brown solids.

In $2015,{ }^{46} \mathrm{Kim}$, Liu and co-workers studied the stereochemistry of polyesters obtained through organocatalyzed Fischer-Inoue-Coates co-polymerization of norbornene anhydrides (NA) $\mathbf{1 g}$ and $\mathbf{1 h}$ with cyclohexene oxide $2 \mathrm{e}$ under various reaction conditions (Scheme 7). Cis(exo-exo) and trans-(exo-endo) microstructures were established by ${ }^{1} \mathrm{H}$ NMR and ${ }^{13} \mathrm{C}$ NMR spectroscopy with the latter featuring, unlike the cis-polymer, two resonances for the methine and vinyl carbons/protons.

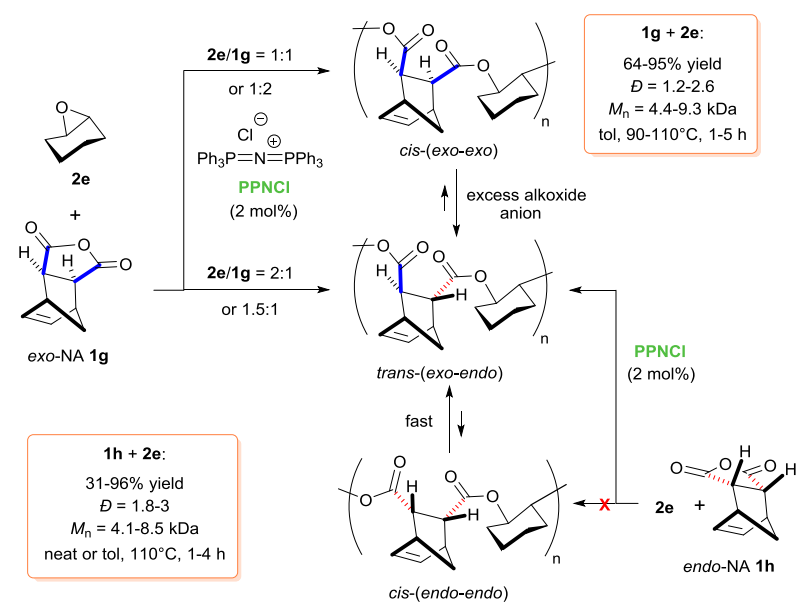

Scheme 7. PPNCl as an initiator in the ROCOP of cyclohexene oxide and norbornene anhydrides according to Kim, Liu and co-workers.

PPNCl was found to be the most efficient initiator for this transformation when compared to various tertiary amines and quaternary onium salts. Highly alternated polyester structures were produced and the less sterically hindered exo-NA 1g, afforded better yields in polyesters than the corresponding endo-NA $\mathbf{1 h}$. The cis-and trans-polymers exhibited moderate molecular weights (4.1-9.3 kDa) with polydispersities ranging from 1.2 to 3.0 and high glass transition temperatures up to 129.8 and $115.9^{\circ} \mathrm{C}$, respectively. Using equimolar amounts or excess of exo-NA $1 \mathrm{~g}$ vs epoxide $2 \mathrm{e}$, afforded only cis-(exo-exo) polyesters 
while excess epoxide $(2 \mathrm{e} / 1 \mathrm{~g}=1.5: 1)$ promoted the exclusive formation of trans-(exo-endo) polyesters. A reasonable explanation lies in the formation of alkoxide anions $\mathbf{1 1}$ (Scheme 8a) when excess epoxide is used: $\mathbf{1 1}$ is basic enough to deprotonate the $\alpha$-carbonyl position of the cis-(exo-exo) polyester to an enolate intermediate, and subsequent protonation to the more thermodynamically stable trans(exo-endo) structure occurs (Scheme 8a). Such a hypothesis was confirmed by adding extra epoxide after completion of a reaction performed at $\mathbf{2 e / 1} \mathbf{g}=1: 1$ : the initially generated cis(exo-exo) polyester was then totally epimerized into the corresponding trans-(exo-endo) product.

Regardless of the reaction conditions and monomers ratio, the cis-(endo-endo) polyester was not observed probably to its more congested nature. Instead, performing the ROCOP with endo-NA $\mathbf{1 h}$ (Scheme 7), only produced the trans-(exo-endo) polyester, showing the occurrence of epimerization during the ROCOP process. Such epimerization was avoided by associating Lewis acid $\mathrm{BEt}_{3}$ (as a co-catalyst) to PPNCl, as shown by $\mathrm{Li}$, Wang and co-workers in 2018 (Schemes $8 \mathrm{~b}$ and 9 ). ${ }^{48}$ Using such a bi-component catalyst, these authors reported a highly regioselective and stereoregular Fischer-Inoue-Coates co-polymerization of several mono-substituted epoxides with tricyclic anhydrides, with a high catalytic activity (TOF up to $330 \mathrm{~h}^{-1}$ for the

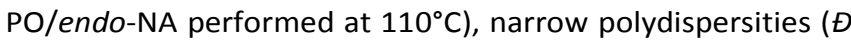
$<1.20$ ) and excellent alternating selectivity (ester linkage > $99 \%)$. The formation of non-basic tetracoordinate $\mathrm{BEt}_{3}$ bonded alkoxide species $\mathbf{1 2}$ upon epoxide ring-opening (Scheme 8b) likely explains the complete absence of epimerization, even in the case of the less stable cis-(endoendo) polyesters. Triethylborane was shown to be the most efficient Lewis acid in the process, electron-deficient analogues $\left(B\left(\mathrm{C}_{6} \mathrm{H}_{5}\right)_{3}, \quad B\left(\mathrm{C}_{6} \mathrm{~F}_{5}\right)_{3}\right)$ decreasing the rate of polymerization and mainly leading to homopolymerization of epoxides. Excess of $\mathrm{BEt}_{3}$ over PPNCl (2:1) also induced the exclusive formation of polyethers. For the ROCOP of $\mathrm{PO} /$ endo-NA, the use of PPNCl alone afforded regioirregular polyesters with very low catalytic activity (TOF $=5 \mathrm{~h}^{-1}$ ) and severe epimerization, in line with Kim, Liu and co-workers' study. ${ }^{46}$ Expectedly, the less sterically hindered exo-NA $\mathbf{~} \mathrm{g}$ was found more reactive than endo-NA $\mathbf{1 h}$ and displayed similar to higher conversions to the corresponding polyesters via ROCOP (Scheme 9).
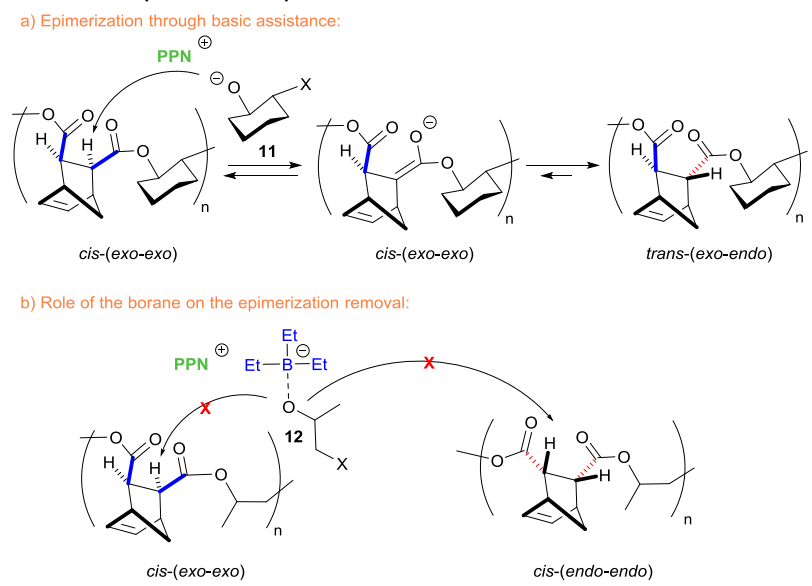

Scheme 8. a) Role of the resulting alkoxide anions in the epimerization of cis-(exo-exo) into trans-(exo-endo) polyesters. b) The formation of non-basic tetracoordinate $\mathrm{BEt}_{3}$-bonded alkoxide species 12 preserves the stereochemical integrity of the cis-(exo-exo) and cis-(endo-endo) polyesters.

Monosubstituted epoxides bearing an electronwithdrawing group $\left(\mathrm{R}=\mathrm{Ph}, \mathrm{CH}_{2} \mathrm{Cl}\right)$ were co-polymerized with cyclic anhydrides more rapidly, and styrene oxide $\mathbf{2} \mathbf{j}$, which is usually prone to ring open on both positions (methine and methylene), still afforded a good regioselectivity in the formation of the polyester with a selective attack at the methylene position. Eventually, enantiopure epoxides S-PO and S-BO epoxides were used for copolymerization with endo-NA to afford highly isotactic enriched polyesters in $98 \%$ ee.

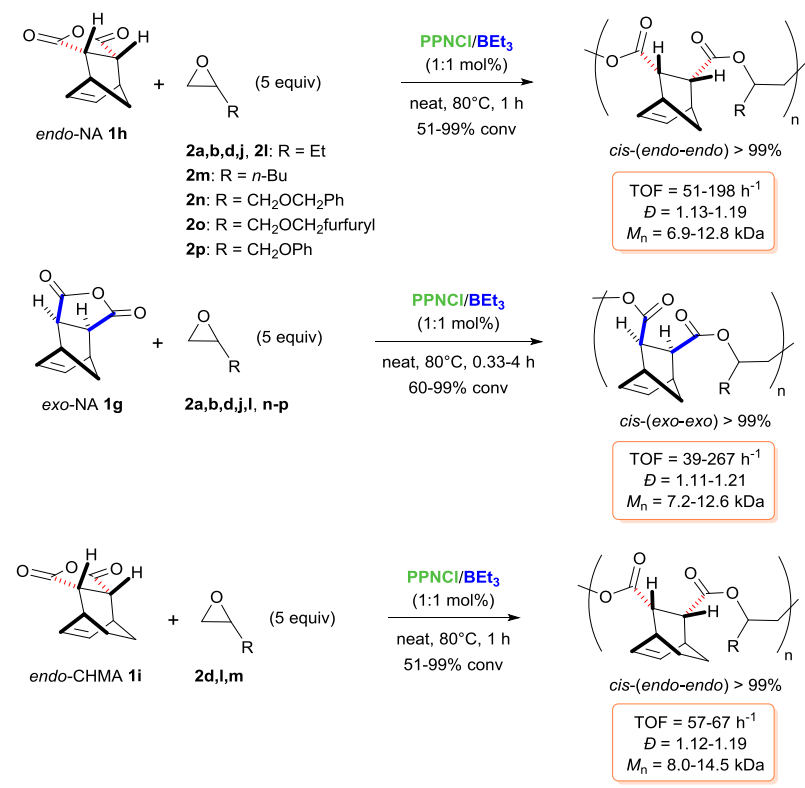

Scheme 9. $\mathrm{BEt}_{3}$ as a co-catalyst with PPNCl in the ROCOP of norbornene anhydrides and epoxides.

Recently, ${ }^{49}$ PPNCl was replaced by DMAP, TBD and DBU as initiators in the co-polymerization of endo-NA $\mathbf{1 h}$ with epoxides $\mathbf{2 d , e , p , q ~ ( S c h e m e ~ 1 0 ) . ~ T h e ~ r e s u l t i n g ~ p o l y e s t e r s ~ w e r e ~}$ produced with moderate to high chain lengths $\left(M_{n}=5.3-31.5\right.$ $\mathrm{kDa}$ ) and polydispersities (ranging from 1.07 to 1.87 ) in more stringent conditions $\left(100{ }^{\circ} \mathrm{C}, 24 \mathrm{~h}\right)$ than those reported by $\mathrm{Li}$, Wang and co-workers ${ }^{48}\left(80{ }^{\circ} \mathrm{C}, 1 \mathrm{~h}\right)$ with no particular improvement except in the case of epoxide $2 \mathrm{~d}\left(M_{\mathrm{n}}=31.5 \mathrm{kDa}\right.$ vs $10.0 \mathrm{kDa}$ ). The produced materials were found to be biocompatible towards human embryonic kidney cells (HEK293), showing more than $80 \%$ cell viability in $72 \mathrm{~h}$. They thus could be used for drug delivery and tissue engineering applications.

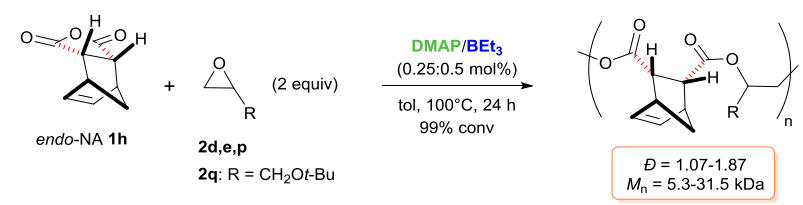

Scheme 10. BEt $\mathrm{B}_{3}$ as a co-catalyst with DMAP in the ROCOP of norbornene anhydride and epoxides. 
It is worth noting that for these endo-norbornene incorporating polyesters, though the cis stereochemistry of diester units is retained, the insertion of the tricyclic anhydrides remained stereoirregular because the process does not desymmetrize these meso-structures (Figure 7).

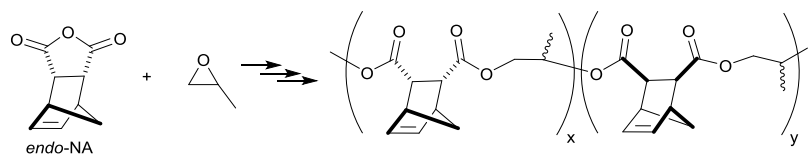

Figure 7. Stereo-irregularity of the polyesters due to nondessymmetrization of the meso structures of cyclic anhydrides as exemplified starting from endo-NA.

The PPNCl/BEt 3 pair was also used by Chakraborty et al. ${ }^{50}$ in the alternate co-polymerization of phthalic anhydride 1a with epoxides $\mathbf{2 e}, \mathbf{q}, \mathbf{r}$, delivering the corresponding polyesters (Scheme 11) in medium to high molecular weights $\left(M_{n}\right.$ up to $57.5 \mathrm{kDa}$ ), and narrow molecular distributions ( $\theta$ as low as 1.07). Contrary to Li, Wang and co-workers, ${ }^{48}$ excess of $\mathrm{BEt}_{3}$ $\left(\mathrm{PPNCl} / \mathrm{BEt}_{3}=1: 2\right)$ led to an alternating ROCOP with the preferential formation of polyesters (esters linkage from 86 to $100 \%$ ) along with polyethers, resulting from epoxide homopolymerization, as minor products. The greater catalytic activity of the borane was explained by its mild Lewis acidity while that of PPNCl lied on its ionic character which induces a faster dissociation of its chloride anion ( $\left.\mathrm{Cl}^{-}\right)$.

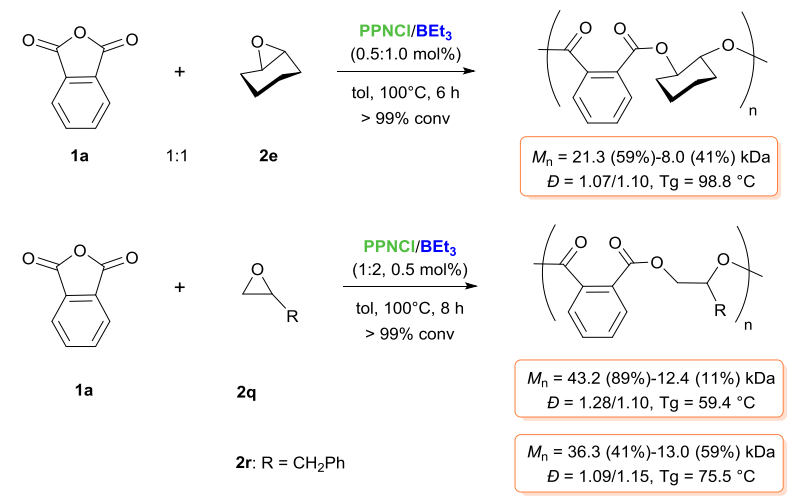

Scheme 11. ROCOP of phthalic anhydride and epoxides $\mathbf{2 e}, \mathbf{2 q}$ and $\mathbf{2 r}$ according to Chakraborty et al.

A good regioselectivity was observed resulting from the preferred $\mathrm{Cl}^{-}$attack at the less hindered methylene position in the case of mono-substituted epoxides $\mathbf{2 q}, \mathbf{r}$ and subsequent polymer chain growth in a perfectly alternating manner. A bimodal molecular weight distribution was always observed for the generated polyesters, which was attributed to the background polymerization initiated by $\mathrm{PPNCl}$ itself. Replacing PPNCl by neutral Lewis bases (DMAP, DBU, TDB) or $\mathrm{BEt}_{3}$ by metallic Lewis acids $\left(\mathrm{AIMe}_{3}, \mathrm{Et}_{2} \mathrm{Zn}\right.$ and $\mathrm{nBu} \mathrm{u}_{2} \mathrm{Mg}$ ) led to side reactions owing to the different basicity/acidity of the corresponding pairs.

A reasonable mechanism was proposed based on in situ NMR experiments (Scheme 12) which showed that the anhydride activation by $\mathrm{BEt}_{3}$ was less favoured than epoxide activation. Mixing $\mathrm{BEt}_{3}$ and $\mathrm{PPNCl}$ first affords a borate which plays the role of an initiator, whose attack on the epoxide results in the formation of the catalytically active alkoxide $\mathbf{1 3 .}$
The latter reacts with anhydride $\mathbf{1 a}$ to deliver $\mathbf{1 4}$ that further reacts with $\mathrm{BEt}_{3}$-activated epoxide to afford $\mathbf{1 5}(\mathrm{n}=0)$, as the first species in the propagation step. As previously described (Scheme 3), the propagation chain then grows through alternate attack of phthalic anhydride 1a and epoxide, the latter corresponding to the rate limiting step of the process. Excess $\mathrm{BEt}_{3}$ ( $v s \mathrm{PPNCl}$ ) plays the role of a catalyst enhancing the positive character of the methylene position of the epoxide through coordination of the epoxide to the boron center.

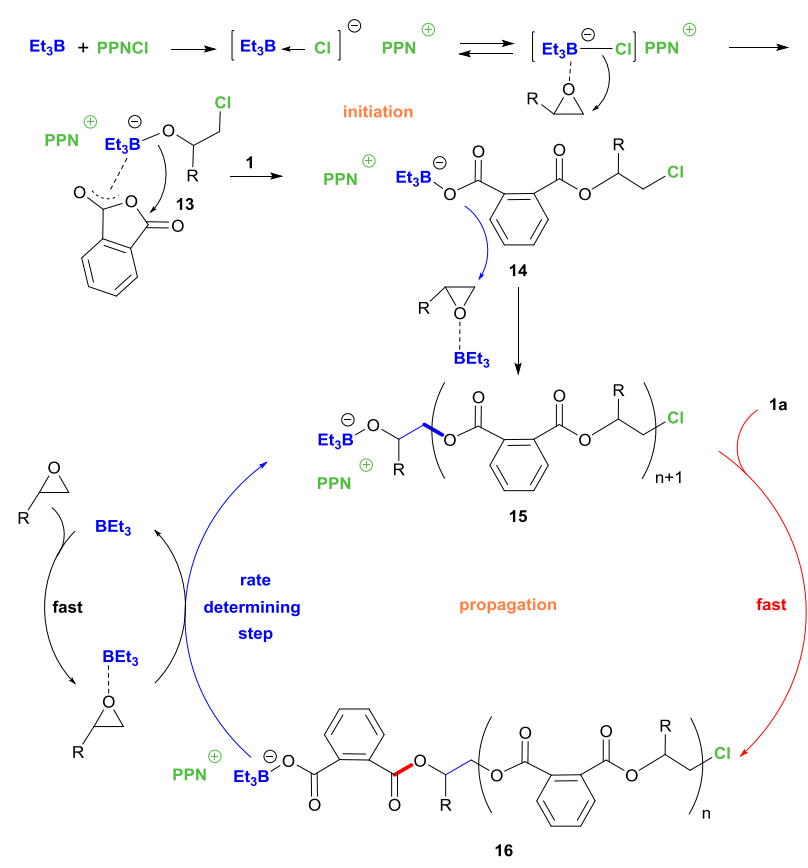

Scheme 12. Proposed mechanism based on in situ NMR studies proposed by Chakraborty et al. for the ROCOP of phthalic anhydride and epoxides.

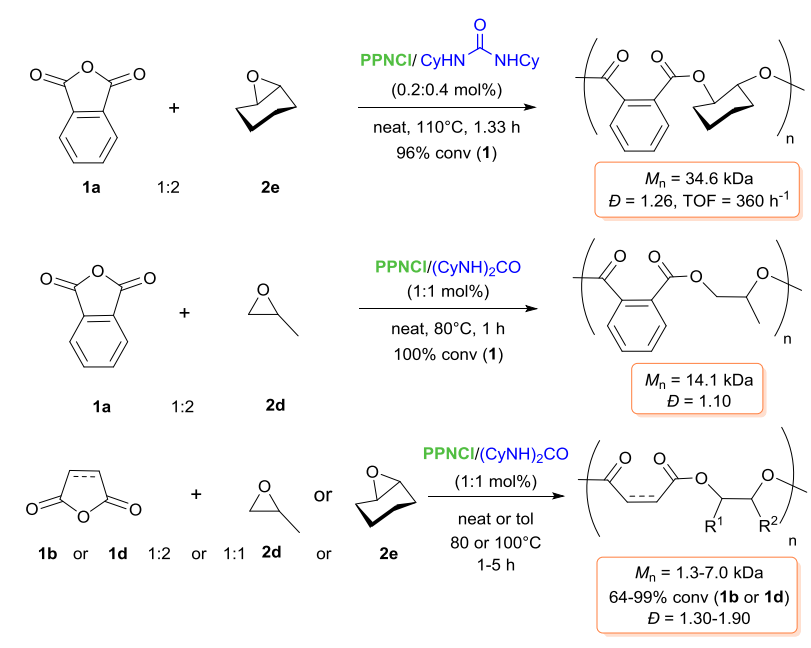

Scheme 13. Hydrogen bond donors as efficient substitutes for $\mathrm{BEt}_{3}$ in the ROCOP of cyclic anhydrides and epoxides as reported by Meng et al..

In a recent study reported by Meng et al., ${ }^{51} \mathrm{BEt}_{3}$ was advantageously (comparing co-polymerization of $\mathbf{1 a}$ and $\mathbf{2 e}$ in schemes 11 and 13) replaced by several (thio)ureas acting as Hydrogen bond donors for monomers activation (Scheme 13). Among them, the less acidic dicyclohexylurea was the 
most efficient, in association with $\mathrm{PPNCl}$, for the copolymerization of phthalic anhydride $\mathbf{1 a}$ and cyclohexene oxide $2 \mathrm{e}$ in a perfectly alternating manner to yield high $M_{\mathrm{n}}$ polyesters (up to $34.6 \mathrm{kDa}$ ) and exceptional TOF (up to $456 \mathrm{~h}^{-}$ ${ }^{1}$ ). More acidic catalysts were suspected to decrease the nucleophilic strength of the reacting anions, which would account for from their lower ROCOP activity and selectivity. Once again, $\mathrm{PPNCl}$ was found to be the most effective nucleophile in comparison with DBU, DMAP or $\left[(i-\mathrm{Bu})_{4} \mathrm{~N}\right] \mathrm{Cl}$. To avoid the presence of phthalic acid resulting from the hydrolysis of the corresponding anhydride (see Table 1), ${ }^{47}$ it was carefully purified by sublimation prior to catalysis, provoking a decrease of its conversion (from 100 to $87-88 \%$ ) but an increase in $M_{n}$ (up to $6.6 \mathrm{kDa}$ ) of the resulting polyesters. Molecular weight of the generated polyesters was improved by increasing monomer/catalyst ratio and the reaction rate was accelerated upon increasing the $(\mathrm{CyNH})_{2} \mathrm{CO} / \mathrm{PPNCl}$ ratio. Polyesters displayed a bimodal GPC pattern albeit with overall narrow polydispersities $(\theta<1.29)$. This catalytic system was used for the synthesis of polyesters derived from the ROCOP of anhydrides $\mathbf{1} \mathbf{a}, \mathbf{b}, \mathbf{d}$ and epoxides 2d,e (Scheme 13).

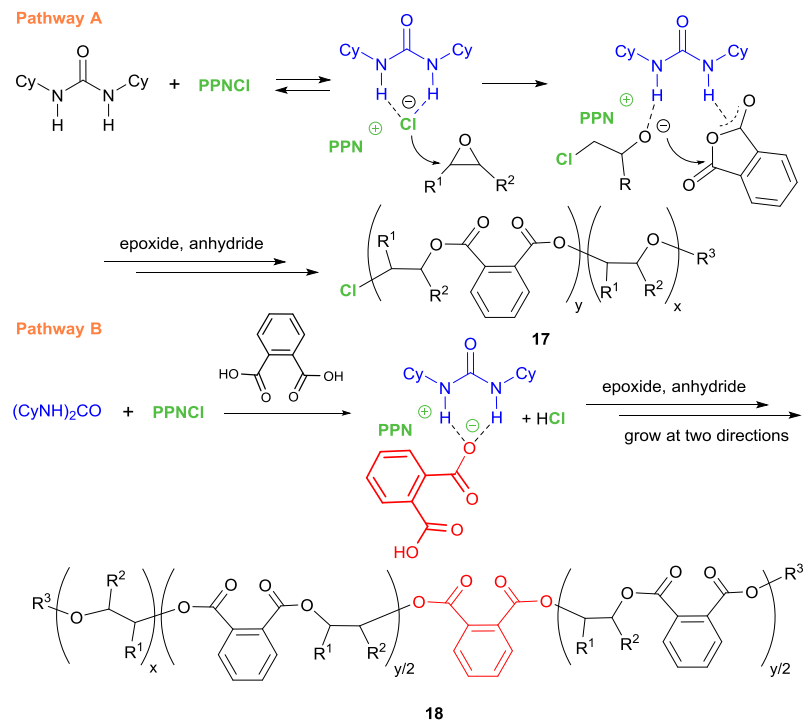

Scheme 14. A reasonable mechanism for the anhydride/epoxide ROCOP mediated by urea-type catalysts.

Reaction of $\mathbf{1 a}$ and $\mathbf{2} \mathbf{d}$ showed a higher activity at lower temperature $\left(M_{\mathrm{n}}=14.1 \mathrm{kDa}, \Theta=1.10\right)$ than the corresponding co-polymerization of $1 \mathrm{a}$ and $2 \mathrm{e}\left(M_{\mathrm{n}}=5.2 \mathrm{kDa}\right.$, $Ð=1.29)$. Replacing $\mathbf{1} \mathbf{a}$ by anhydrides $\mathbf{1 b}$ and $\mathbf{1} \mathbf{d}$ led to lower conversions (Scheme 13). Deprotonation of the latter (1 $\mathbf{b}$ and 1d) by $\mathrm{DBU}$ or $\mathrm{PPNCl}$ and subsequent deactivation of these initiators, as proposed by the authors, is unlikely given the relative acidities of the species involved.

Based on a previous report, ${ }^{47}$ two pathways were proposed (Scheme 14, $R^{3}=H$ ). In pathway $A$, the chloride anion initiates the process by ring opening an epoxide and the chain propagates at one direction through alternating addition of anhydride and epoxide. When diacid is present (as an impurity in the anhydride starting material), pathway $B$ can explain the formation of the resulting polymer with the chain growing in two directions.

The co-polymerization of cyclic anhydrides $\mathbf{1 a}$ and $\mathbf{1} \mathbf{d}$ with 2d was performed in 2019 by Zhang et al., ${ }^{52}$ using a borane/base combination as catalysts (Scheme 15). As previously reported for the ROCOP of norbornene anhydrides and several epoxides (Scheme 9), ${ }^{48} \mathrm{BEt}_{3}$ was the more efficient Lewis acid in the process when compared to $B\left(\mathrm{C}_{6} \mathrm{H}_{5}\right)_{3}$ and $\mathrm{B}\left(\mathrm{C}_{6} \mathrm{~F}_{5}\right)_{3}$, for both steric and electronic reasons.
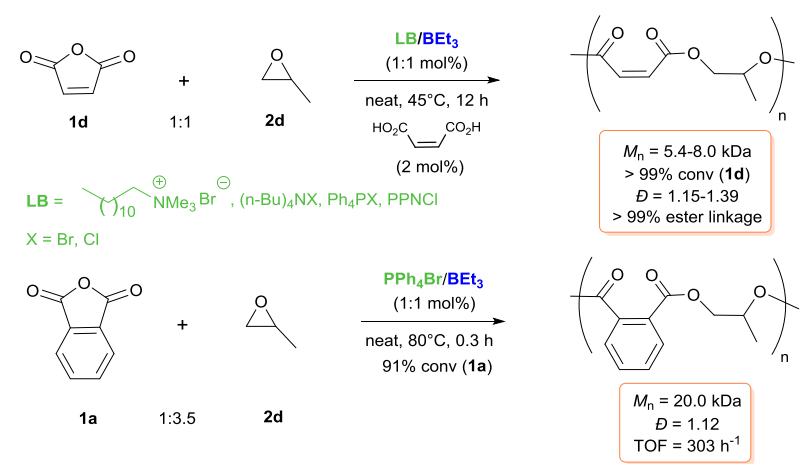

Scheme 15. ROCOP of maleic anhydride and propene oxide catalyzed by various Lewis pairs.

Once again, PPNCl was found superior to other bases used and the presence of maleic acid ( $2 \mathrm{~mol} \%$ ) was shown to be essential for high conversion and the production of polyesters with $M_{\mathrm{n}}$ values higher than $5 \mathrm{kDa}$. A few other cyclic anhydrides and epoxides were also polymerized with no particular improvement when compared to earlier studies. Phthalic anhydride 1a was co-polymerized with propene oxide $\mathbf{2 d}$ giving the corresponding polyester (Scheme 15) under similar conditions to those reported by Cramail, Hošt'álek and co-workers (Figure 6).
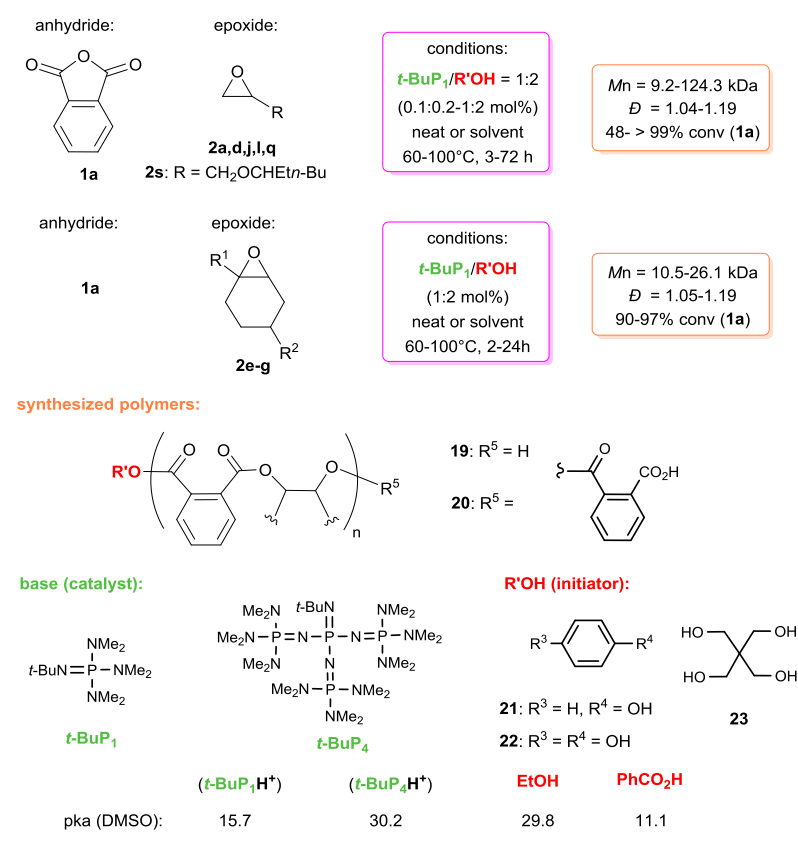

Figure 8. Results of the ROCOP of phthalic anhydride and epoxides according to Zhao et al.'s work using phosphazenes as catalysts and alcohols as initiators. 
Phosphazenes are organic superbases that have recently attracted significant attention for use as catalysts/initiators in anionic polymerization of various monomers ranging from epoxides, cyclosiloxanes to vinyl and diene monomers. ${ }^{53}$ The first use of phosphazenes as catalysts in Fischer-Inoue-Coates co-polymerizations (Figure 8) was reported by Zhao et al. in a seminal work in 2017, ${ }^{54}$ extended in a full paper one year later. ${ }^{55} t-\mathrm{BuP}_{1}$ is thus an efficient catalyst, in combination with an alcohol source as an initiator, for the copolymerization of several epoxides with anhydride $\mathbf{1 a}$. Polyesters $\mathbf{1 9}$ or $\mathbf{2 0}$ are produced with perfectly alternating sequence distribution, well controlled molecular weights (9.2-124.3 kDa) and low polydispersities $(\theta=1.04-1.19)$. Sequential addition of two different epoxides also allowed the formation of block-alternating co-polymers owing to the living nature of the ROCOP. When 1,4-benzenedimethanol 22 or pentaerythritol $\mathbf{2 3}$ were used as polymerization initiators, 2- or 4-arm polyesters were respectively generated. The high purity of phthalic anhydride 1a was essential to avoid bimodal distributions due to the detrimental presence of phthalic acid. $t$-BuP 1 was easily recovered and reused with success.

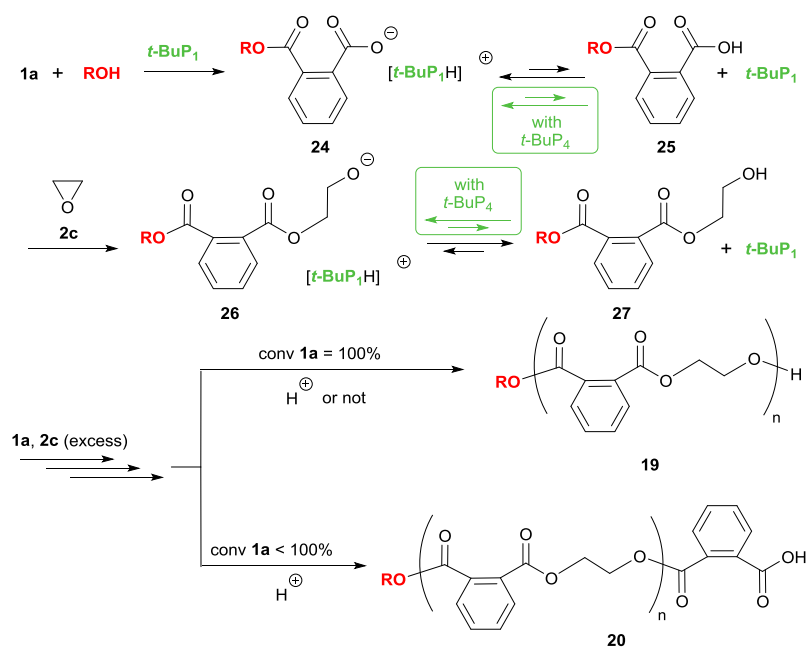

Scheme 16. A possible mechanism for the ROCOP of phthalic anhydride with epoxides (described here for ethylene oxide) catalyzed by phosphazenes.

Replacing $t$-BuP 1 by $t$ - $\mathrm{BuP}_{4}$ when reacting anhydride $\mathbf{1 a}$ and ethylene oxide $\mathbf{2} \mathbf{c}$ in the presence of benzyl alcohol as an initiator, led to the formation of an alternating copolymer with a broader polydispersity $(\theta=1.32)$ and shorter chain length polyesters $\left(M_{\mathrm{n}}=3.2 \mathrm{kDa}\right)$ compared to the corresponding $M_{\mathrm{n}}$ theoretical value, indicating the extensive occurrence of transesterification reactions in that case. Such a difference between the two phosphazene catalysts can be explained by their relative basicity (Figure 8, pKa (DMSO) of the conjugated acids of $t-\mathrm{BuP}_{1}$ and $t-\mathrm{BuP}_{4}$ are respectively 15.7 and 30.2) compared to the acidity of the alcohol motif $\mathrm{CH}_{2} \mathrm{CH}_{2} \mathrm{OH}$ (pKa similar to EtOH $=29.8$ in DMSO) or benzoic acid moiety $\mathrm{RPhCO}_{2} \mathrm{H}$ (pKa similar to $\mathrm{PhCO}_{2} \mathrm{H}$ : = 11.1 in DMSO) found as intermediates of the propagation step. Indeed, as depicted in scheme 16, a reasonable mechanism likely involves $t$ - $\mathrm{BuP}_{4}$ that readily deprotonates both $\mathrm{CH}_{2} \mathrm{CH}_{2} \mathrm{OH}$ and $\mathrm{RPhCO}_{2} \mathrm{H}$ terminals while $t$ - $\mathrm{BuP}_{1}$ can only deprotonate the latter. This leads in the former case to the presence of very nucleophilic alkoxide species (26 in the initiation step) all along the co-polymerization prone to induce intramolecular or intermolecular transesterifications. In contrast, with $t$-BuP ${ }_{1}$, the formation of such alkoxides is clearly disfavoured (as exemplified by the preferred formation of $\mathbf{2 7}$ in the initiation step) thus avoiding detrimental chain transfer/back biting reactions as the ROCOP proceeds.

Recently, Li et al. reported the Fischer-Inoue-Coates copolymerization of phthalic anhydride $\mathbf{1 a}$ and cyclohexene oxide 2e catalyzed by cyclic trimeric phosphazene base (CTPB) and initiated by a Brønsted acid (Scheme 17). ${ }^{56}$ Various well-defined alternating polyesters $\left(M_{\mathrm{n}}=6.0-15.8\right.$ $\mathrm{kDa}, \quad \theta=1.10-1.66)$ were produced with anhydride conversions ranging from 57 to $99 \%$. Excess epoxide 2 e over anhydride $1 \mathrm{a}$ at $\mathrm{CTPB} / \mathrm{PhCO}_{2} \mathrm{H}=1: 1$ ratio resulted in partial epoxide homopolymerization, attributed to CTPB basicity. It was partially neutralized working with an excess of acid ( $\mathrm{CTPB} / \mathrm{PhCO}_{2} \mathrm{H}=0.5: 1$ ) and led to the production of a welldefined polyester material exhibiting a monomodal GPC trace. In 2020, ${ }^{57}$ the same authors performed a similar study but using a Lewis acid such as $\mathrm{BEt}_{3}$ as co-catalyst in the presence/absence of $\mathrm{BnOH}$ as an initiator (Scheme 17) for the co-polymerization of phthalic anhydride 1 a with epoxides $\mathbf{2 d}, \mathbf{e}, \mathbf{I}$ CTPB alone led to no polymerization while in the presence of $\mathrm{BnOH}$, under similar conditions, 56 to $99 \%$ conversion of anhydride was observed $\left(60-100^{\circ} \mathrm{C}, 10-48 \mathrm{~h}\right)$.

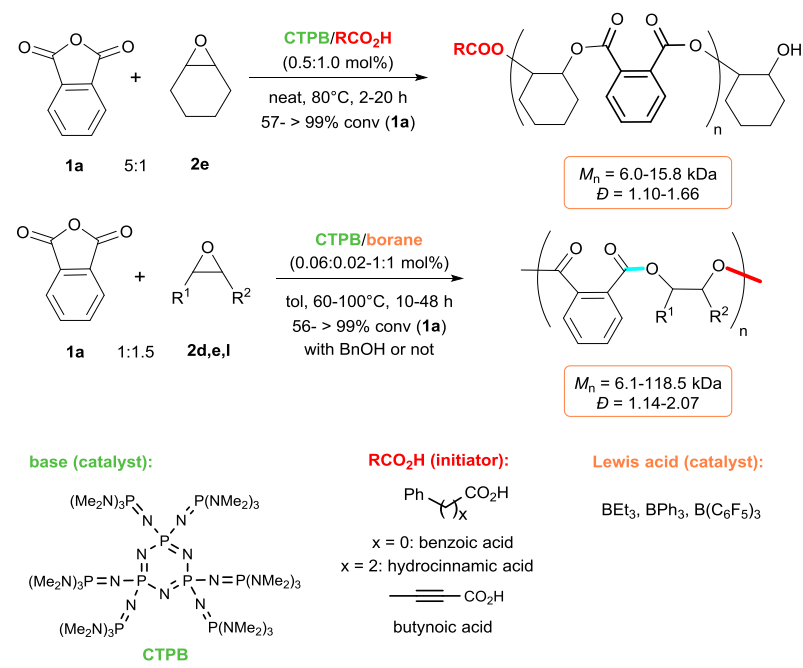

Scheme 17. Results of the ROCOP of phthalic anhydride and epoxides using phosphazenes acids and boranes.

Addition of $\mathrm{BEt}_{3}$ increased anhydride conversion (99\%) and permitted a shorter reaction time (10 h). Higher molecular weights were obtained in the transformation $(9.0$ to $118.5 \mathrm{kDa}$ ) upon increasing the epoxide/anhydride/CTPB/BEt 3 ratio from 150/100/1/1 to $7500 / 5000 / 3 / 1$, but this also resulted into broader polydispersity values $(\theta=1.21$ to 2.07$)$.

As previously noted with the $\mathrm{BEt}_{3} / \mathrm{PPNCl}$ catalytic system, ${ }^{48} \mathrm{BEt}_{3}$ was also found to be more effective than more electron-deficient analogues $\left(\mathrm{B}_{(}\left(\mathrm{C}_{6} \mathrm{H}_{5}\right)_{3}, \mathrm{~B}\left(\mathrm{C}_{6} \mathrm{~F}_{5}\right)_{3}\right)$. Zhang and co-workers also reported ${ }^{58}$ the Fischer-Inoue-Coates co- 
polymerization of succinic anhydride $\mathbf{1} \mathbf{b}$ and propylene oxide 2d catalyzed by several organoborane/Lewis base pairs (Scheme 18).
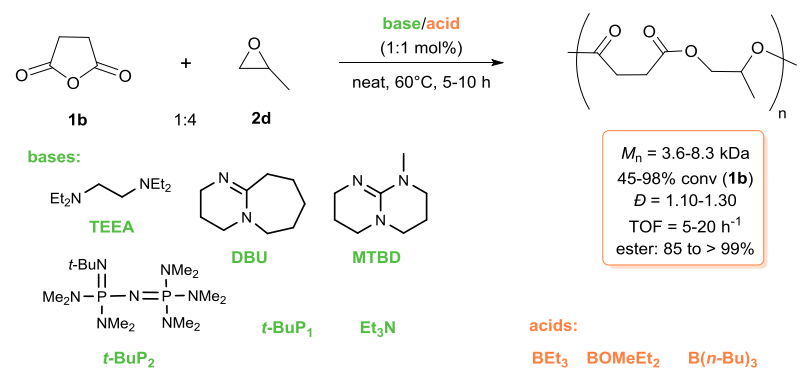

Scheme 18. Results of the ROCOP of succinic anhydride and propylene oxide according to Zhang et al. using Lewis base/organoborane pairs as catalytic systems.

The corresponding materials were obtained with high ester content (up to > 99\%), moderate to excellent conversions (45-98\%), narrow polydispersities ( $\theta=1.10-1.30)$ and molecular weights ranging from 3.6 to $8.3 \mathrm{kDa}$, thus higher than an earlier study. ${ }^{51}$ Using a $\mathrm{BEt}_{3} / t-\mathrm{BuP}_{1}$ pair as catalyst in a $4 / 1$ ratio at $80^{\circ} \mathrm{C}$, led to a much higher TOF value $\left(128 \mathrm{~h}^{-1}\right)$ yet at the expense of the resulting material chain length $\left(M_{\mathrm{n}}=1.7 \mathrm{kDa}, \theta=1.24\right)$. It was evidenced that increasing basicity leads to higher TOFs in the following order TEA $\left(7 \mathrm{~h}^{-1}\right)<\operatorname{DBU}\left(9 \mathrm{~h}^{-1}\right)<\operatorname{MTBD}\left(11 \mathrm{~h}^{-1}\right)<t-\operatorname{BuP}_{1}\left(15 \mathrm{~h}^{-1}\right)<t$ $\operatorname{BuP}_{2}\left(20 \mathrm{~h}^{-1}\right)$ except for TEEA, a double site initiator.

\section{Conclusions} Organo-catalyzed/initiated Fischer-Inoue-Coates co-
polymerization, when compared to metal catalyzed processes, remains essentially in its infancy as evidenced by the limited number of publications (only 13) dedicated to this topic since its revival 2015.

PPNCl and $t-\mathrm{BuP}_{1}$ on the one hand as bases and $\mathrm{BEt}_{3}$ and dicyclohexylurea $(\mathrm{CyNH})_{2} \mathrm{CO}$ on the other hand as acids, appear to date as the most efficient base and acid initiators/catalysts for this transformation. As mentioned by several reports, particular attention must be paid to the purity of the monomers, ${ }^{47}$ and especially that of the anhydrides which are easily hydrolyzed into the corresponding diacids promoting side reactions, subsequent decrease of molecular weights and the ill-defined nature of the resulting material. In the same vein, the presence of alkoxide species in the reaction mixture, due to the use of strong bases as initiators, may lead to intra- or intermolecular transesterifications which are detrimental to polymerization control and thus materials properties. The homopolymerization of epoxides, attributed to excessive activation by strong Lewis acids ${ }^{48}$ or the use of strong bases, ${ }^{56}$ is also an obstacle to a well-behaved alternating ROCOP of anhydrides and epoxides.

The comparison of the efficiency of the organocatalysts used in the Fischer-Inoue-Coates reaction is not straightforward given the diversity of the monomers employed. Nevertheless, copolymerization of phthalic anhydride $\mathbf{1 a}$ and cyclohexene oxide $\mathbf{2 e}$ can be taken as a reference reaction since such combination has been studied with most organocatalytic systems. Table 2 summarizes the six organocatalyzed thus far reported and a recent highly effective metal catalyzed ROCOP of $1 \mathrm{a}$ and $2 e^{45 i}$ It can be seen that the organocatalytic system using a urea-type catalyst (entry 6) is competitive with a metallic catalyst (entry 7), confirming the pertinence of the metal-free approach catalysis (greener conditions) and justifying its growing significance and importance in ROCOP catalysis. 
Table 2. Comparison of organocatalyzed co-polymerization (entry 1-6) of phthalic anhydride and cyclohexene oxide with the best reported result obtained with a chromium complex (entry 7).

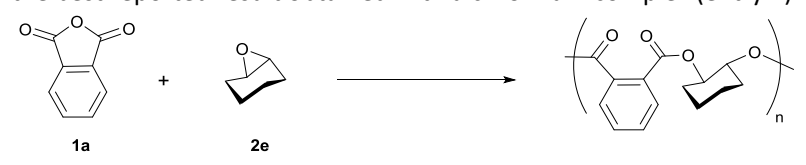

\begin{tabular}{|c|c|c|c|c|c|c|c|c|}
\hline entry & ref & $1 a / 2 e$ & catalytic system & conditions & $\begin{array}{l}\text { Conv } \\
(\%)\end{array}$ & $M_{\mathrm{n}}(\mathrm{kDa})$ & $\theta$ & $\operatorname{Tg}\left({ }^{\circ} \mathrm{C}\right)$ \\
\hline 1 & 47 & 1:1 & $\operatorname{PPNCl}(0.4 \mathrm{~mol} \%)$ & tol, $110^{\circ} \mathrm{C}, 10 \mathrm{~h}$ & 93 & 14.5 (bimodal) & 1.49 & 138 \\
\hline 2 & 57 & $1: 1.5$ & $\mathrm{CTPB} / \mathrm{BEt}_{3}(1.0: 1.0 \mathrm{~mol} \%)$ & tol, $60^{\circ} \mathrm{C}, 10 \mathrm{~h}$ & $>99$ & 6.1 & 1.26 & 140.2 \\
\hline 3 & 56 & 1:5 & $\mathrm{CTPB} / \mathrm{PhCO}_{2} \mathrm{H}(0.16: 0.33 \mathrm{~mol} \%)$ & neat, $80^{\circ} \mathrm{C}, 6 \mathrm{~h}$ & $>99$ & 15.8 & 1.10 & - \\
\hline 4 & 50 & 1:1 & $\mathrm{PPNCl} \mathrm{BEt}_{3}(0.5: 1.0 \mathrm{~mol} \%)$ & tol, $60^{\circ} \mathrm{C}, 6 \mathrm{~h}$ & $>99$ & $21.3(59 \%) / 8(41 \%)$ & $1.07 / 1.1$ & 98.8 \\
\hline 5 & 55 & $1: 1.5$ & $t$-BuP $1 / \mathrm{Ph}(\mathrm{OH})_{2}(1.0: 2.0 \mathrm{~mol} \%)$ & neat, $100^{\circ} \mathrm{C}, 2 \mathrm{~h}$ & 96 & 18.4 & 1.06 & - \\
\hline 6 & 51 & $1: 2$ & $\mathrm{PPNCl} /(\mathrm{CyNH})_{2} \mathrm{CO}(0.2: 0.4 \mathrm{~mol} \%)$ & neat, $100^{\circ} \mathrm{C}, 1.33 \mathrm{~h}$ & 96 & $34.6 \mathrm{kDa}$ & 1.26 & - \\
\hline 7 & $45 i$ & $1: 2$ & “Cr"/DMAP (0.12:0.62 mol\%) & neat, $100{ }^{\circ} \mathrm{C}, 5 \mathrm{~h}$ & 92 & $43.8 \mathrm{kDa}$ & 1.21 & 126 \\
\hline
\end{tabular}


As new perspective in the field, terpolymerization appears as an interesting direction to access well-defined novel materials with broader properties and applications. Based on the Fischer-Inoue-Coates co-polymerization, poly(ester- $b$ ethers) triblock copolymers and pentablock terpolymers have already been synthesized using Lewis pairs (DBU/BEt ${ }_{3}$, phosphazene/ $\mathrm{BEt}_{3}, t$-BuP $\mathrm{B}_{1} / \mathrm{diol}$ ) as organocatalytic systems with excess epoxides and additional $L$-lactide respectively. ${ }^{59}$

Enantioselective Fischer-Inoue-Coates co-polymerizations are also of potential interest. Contrary to metal catalyzed routes that have already seen a few successful developments in this area, most of the polyesters prepared through organocatalysis are atactic up to date. The first approach to access enantiomerically enriched polyesters may consist in the polymerization of enantiomerically pure monomers. Mixing opposite enantiomers of parent polymers led to the formation of polymer stereocomplex ${ }^{60}$ with enhanced thermal properties. ${ }^{61}$ The second approach relies on the design of homochiral catalysts able to stereo-discriminate meso or racemic monomers. Such a strategy was recently successfully applied for the copolymerization of meso-epoxides and cyclic anhydrides catalyzed by enantiopure dinuclear $\mathrm{Al}(\mathrm{III})$ complexes. ${ }^{62}$ It was also utilized for the preparation of isotactic polyesters via an unprecedented kinetic resolution of racemic epoxides catalyzed by $\mathrm{Al}(\mathrm{III})$ or $\mathrm{Co}$ (III) complexes. ${ }^{63}$ Owing to the large pool of chiral organic molecules available, the design of homochiral organocatalysts for the Fischer-Inoue-Coates copolymerization appears as a large and potentially prolific field of investigation. Initially, this can be done through the use of organocatalysts known for their effectiveness in epoxide opening reactions. ${ }^{64}$ Synthesis of enantiomerically pure cyclic anhydrides which have received little attention compared with epoxides, would also be of importance when looking for future prospects in the Fischer-Inoue-Coates co-polymerization.

The final challenge will be to develop catalysts that are as efficient in terms of $M_{n}$ of the resulting polymers and activity as those based on metal catalysts.

Since the beginning of the $20^{\text {th }}$ century, human productivity has increased exponentially and so did the demand for nonrenewable resources such as petroleum-based thermoplastics ( $8 \%$ of oil production is dedicated to plastics production: $4 \%$ of raw material and $4 \%$ for the energy to produce plastics). The use of fossil resources-based products is now facing two major world issues: environmental pollution and shortage of resources. The depletion of fossil fuels, reinforced by the growing demand from emerging countries, imposes the search for new deposits which are less profitable due to the nature of the crude (bituminous shale) or their inaccessibility (deep water drilling project, shale gases...). In that context, the need for polymers of renewable origin, which represent less than $1 \%$ of total worldwide polymer production today, ${ }^{65}$ is required to sharply increase in the coming years. The Fischer-InoueCoates co-polymerization must be part of these future developments which rely on the production of bio-based molecules, ${ }^{66}$ chemical compounds that entirely originate from biomass (i.e. material of biological origin excluding fossil carbon sources).

\section{Conflicts of interest}

There are no conflicts to declare.

\section{Acknowledgements}

This work benefited from the financial support of TOTAL SA within the framework of a call for exploratory projects coordinated by TOTAL SA and the CNRS (Cellule énergie).

Authors acknowledge support of this project by CNRS, Université Paris-Saclay, ANR (CoCaBio ANR-19HC2503). The ANR is gratefully acknowledged for a doctoral fellowship to G. P. and a post-doctoral fellowship to D. R.

\section{Notes and references}

1 a) D. A. Olson, S. E. A. Gratton, J. M. DeSimone and V. V. Sheares, J. Am. Chem. Soc. 2006, 128, 13625-13633; b) R.-J. Müller, I. Kleeberg and W.-D. Deckwer, J. Biotechnol. 2001, 86, 87-95; c) A. H. Brown and V. V. Sheares, Macromolecules 2007, 40, 4848-4853.

2 a) A. J. Ragauskas, C. K. Williams, B. H.Davison, G. Britovsek, J. Cairney, C. A. Eckert, W. J. Frederick, J. P. Hallett, D. J. Leak, C. L. Liotta, J. R. Mielenz, R. Murphy, R. Templer and T. Tschaplinski, Science 2006, 311, 484-489; b) R. A. Gross and B. Kalra, Science 2002, 297, 803-807; c) M. A. Hillmyer and W. B. Tolman, Acc. Chem. Res. 2014, 47, 2390-2396; d) M. Vert, Biomacromolecules 2005, 6, 538-546; e) W. Amass, A. Amass and B. Tighe, Polym. Int. 1998, 47, 89-144.

3 G. Odian, Principles of Polymerization, 4th ed.; John Wiley \& Sons: Hoboken, NJ, 2004.

4 P. Lecomte and C. Jerôme, Recent Developments in RingOpening Polymerization of Lactones. In Synthetic Biodegradable Polymers; Rieger, B., Künkel, A., Coates, G. W., Reichardt, R., Dinjus, E., Zevaco, A. T., Eds.; Advances in Polymer Science, Vol. 245; Springer-Verlag: Berlin and Heidelberg, Germany, 2012; pp 173-217.

5 a) J. M. Longo, M. J. Sanford and G. W. Coates, Chem. Rev. 2016, 116, 15167-15197; b) S. Paul, Y. Zhu, C. Romain, R. Brooks, P. K. Saini, C. K. Williams, Chem. Commun. 2015, 51, 6459-6479.

6 R. F. Fischer, J. Polym. Sci. 1960, 44, 155-172.

7 T. Tsuruta, K. Matsuura and S. Inoue, Makromolekular Chem. 1964, 64, 211-214.

8 R. C. Jeske, A. M. DiCiccio and G. W. Coates, J. Am. Chem. Soc. 2007, 129, 11330-11331.

9 F. Hong, J. Iron Steel Res, Int 2006, 13, 33-38.

$10 \mathrm{H}$. Kozlowski, P. Kolkowska, J. Watly, K. Krzywoszynska and S. Potocki, Cur. Med. Chem. 2014, 21, 3721-3740.

11 a) C. Exley, Morphologie 2016, 100, 51-55; b) S. V. Verstraeten, L. Aimo and P. I. Oteiza, Arch. Toxicol. 2008, 82, 789-802.

12 M. C. Tanzi, P. Verderio, M. G. Lampugnani, M. Resnati, E. Dejana and E. Sturani, J. Mater. Sci. Mater. Med. 1994, 5, 393-396.

13 K. A. Ahrendt, C. J. Borths and D. W. C. MacMillan, J. Am. Chem. Soc. 2000, 122, 4243-4244.

14 a) W. N. Ottou, H. Ren Sardon, D. Mecerreyes, J. Vignolle and D. Taton, Prog. Polym. Sci. 2016, 56, 64-115; b)_M. K. Kiesewetter, E. J. Shin, J. L. Hedrick and R. M. Waymouth, 
Macromol. 2010, 43, 2093-2107; c) A. Bossion, K. V. Heifferon, L. Meabe, N. Zivic, D. Taton, J. L. Hedrick, T. E. Long and H. Sardon, Prog. Polym. Sci. 2019, 90, 164-210; d) Q.-L. Song, S.-Y. Hu, J.-P. Zhao and G.-Z. Zhang, Chin. J. Polym. Sci. 2017, 35, 581-601; e) M. Fèvre, J. Pinaud, Y. Gnanou, J. Vignolle and D. Taton, Chem. Soc. Rev. 2013, 42, 2142-2172.

15 P. Flory, J. J. Am. Chem. Soc. 1940, 62, 2261-2264.

16 S. Pappuru and D. Chakraborty, Eur. Polym. J. 2019, 121, 109276.

17 F. Nederberg, E. F. Connor, M. Möller, T. Glauser and J. L. Hedrick, Angew. Chem. Int. 2001, 40, 2712-2715.

18 M. Myers, E. F. Connor, T. Glauser, A. Möck, G. Nyce and J. L. Hedrick, J. Polym. Sci. A Polym. Chem. 2002, 40, 844-851.

19 a) E. F. Connor, G. W. Nyce, M. Myers, A. Möck and J. L. Hedrick, J. Am. Chem. Soc. 2002, 124, 914-915. b) G. W. Nyce, T. Glauser, E. F. Connor, A. Möck, R. M.Waymouth and J. L. Hedrick, J. Am. Chem. Soc. 2003, 125, 3046-3056. c) O. Coulembier, A. P. Dove, R. C. Pratt, A. C. Sentman, D. A. Culkin, L. Mespouille, P. Dubois, R. M. Waymouth and J. L. Hedrick, Angew. Chem. Int. Ed. 2005, 44, 4964-4968.

20 a) A. P. Dove, R. C. Pratt, B. G. G. Lohmeijer, R. M. Waymouth and J. L. Hedrick, J. Am. Chem. Soc. 2005, 127, 13798-13799. b) R. C. Pratt, B. G. G. Lohmeijer, D. A. Long, P. N. P. Lundberg, A. P. Dove, H. Li, C. G. Wade, R. M. Waymouth and J. L. Hedrick, Macromolecules 2006, 39, 7863-7871. c) B. G. G. Lohmeijer, R. C. Pratt, F. Leibfarth, J. W. Logan, D. A. Long, A. P. Dove, F. Nederberg, J. Choi, C. Wade, R. M. Waymouth and J. L. Hedrick, Macromolecules 2006, 39, 8574-8583.d) O. T. du Boullay, N. Saffon, J.-P. Diehl, B. Martin-Vaca and D. Bourissou, Biomacromolecules 2010, 11, 1921-1929. e) O. I. Kazakov and M. K. Kiesewetter, Macromolecules 2015, 48 , 6121-6126. f) S. S. Spink, O. I. Kazakov, E. T. Kiesewetter and M. K. Kiesewetter, Macromolecules 2015, 48, 6127-6131. g) K. V. Fastnacht, S. S. Spink, N. U. Dharmaratne, J. U. Pothupitiya, P. P. Datta, E. T. Kiesewetter and M. K. Kiesewetter, ACS Macro Lett. 2016, 5, 982-986. h) X. Zhang, G. O. Jones, J. L. Hedrick and R. M. Waymouth, Nat. Chem 2016, 8, 1047-1053.

21 J.-B. Zhu and E. Y.-X. Chen, J. Am. Chem. Soc. 2015, 137 12506-12509.

22 a) N. U. Dharmaratne, J. U. Pothupitiya, T. J. Bannin, O. I. Kazakov and M. K. Kiesewetter, ACS Macro Lett. 2017, 6 421-425. b) S. Xu, H. Sun, J. Liu, J. Xu, X. Pan, H. Dong, Y. Liu, Z. Li and K. Guo, Polym. Chem. 2016, 7, 6843-6853. c) B. Lin and R. M. Waymouth, J. Am. Chem. Soc. 2017, 139, 16451652.

23 R. C. Pratt, B. G. Lohmeijer, D. A. Long, R. M. Waymouth and J. L. Hedrick, J. Am. Chem. Soc. 2006, 128, 4556-4557.

24 a) J. Liu, C. Chen, Z. Li, W. Wu, X. Zhi, Q. Zhang, H. Wu, X. Wang, S. Cui and K. Guo, Polym. Chem. 2015, 6, 3754-3757. b) D. Specklin, F. Hild, L. Chen, L. Thévenin, M. Munch, F. Dumas, F. Le Bideau and S. Dagorne, ChemCatChem 2017, 9 3041-3046. c) A. Rostami, E. Sadeh and S. Ahmadi, J. Polym Sci. A Chem. 2017, 55, 2483-2493. d) J. Liu, J. Xu, Z. Li, S. Xu, X. Wang, H. Wang, T. Guo, Y. Gao, L. Zhang and K. Guo, Polym. Chem. 2017, 8, 7054-7068.

25 O. Coulembier, D. P. Sanders, A. Nelson, A. N. Hollenbeck, H. W. Horn, J. E. Rice, M. Fujiwara, P. Dubois and J. L. Hedrick, Angew. Chem. Int. Ed. 2009, 48, 5170-5173.

26 C. Thomas, F. Peruch, A. Deffieux, A. Milet, J.-P. Desvergne and B. Bibal, Adv. Synth. Catal. 2011, 353, 1049-1054.

27 a) S. Koeller, J. Kadota, A. Deffieux, F. Peruch, S. Massip, J.-M. Léger, J.-P. Desvergne and B. Bibal, J. Am. Chem. Soc. 2009, 131, 15088-15089. b) S. Koeller, J. Kadota, F. Peruch, A Deffieux, N. Pinaud, I. Pianet, S. Massip, J.-M. Léger, J.-P. Desvergne and B. Bibal, Chem. Eur. J. 2010, 16, 4196-4205.
28 L. Zhang, F. Nederberg, R. C. Pratt, R. M. Waymouth, J. L. Hedrick and C. G. Wade, Macromolecules 2007, 40, 41544158.

29 S. Gazeau-Bureau, D. Delcroix, B. Martín-Vaca, D. Bourissou, C. Navarro and S. Magnet, Macromolecules 2008, 41, 37823784.

30 K. Makiguchi, T. Satoh and T. Kakuchi, Macromolecules 2011, 44, 1999-2005.

31 A. Alba, A. Schopp, A.-P. De Sousa Delgado, R. Cherif-Cheikh, B. Martín-Vaca and D. Bourissou, J. Polym. Sci. A Polym. Chem. 2010, 48, 959-965.

32 Z. Grobelny, M. Matlengiewicz, J. Jurek-Suliga, S. Golba and K. Skrzeczyna, Polym. Bull. 2018, 75, 1101-1121.

33 J. Herzberger, K. Niederer, H. Pohlit, J. Seiwert, M. Worm, F. R. Wurm and H. Frey, Chem. Rev. 2016, 116, 2170-2243.

34 B. Eßwein, N. M. Steidl and M. Möller, Macromol. Rapid Commun. 1996, 17, 143-148.

35 Up to 2016 see ref. 34. a) J. Zhao, D. Pahovnik, Y. Gnanou and N. Hadjichristidis, Macromolecules 2014, 47, 1693-1698. b) Y. Xia, Y. Chen, Q. Song, S. Hu, J. Zhao and G. Zhang, Macromolecules 2016, 49, 6817-6825.

36 a) Y. Chen, J. Shen, S. Liu, J. Zhao, Y. Wang and G. Zhang, Macromolecules 2018, 51, 8286-8297. b) C.-J. Zhang, H.-Y. Duan, L.-F. Hu, C.-H. Zhang and X.-H. Zhang, ChemSusChem 2018, 11, 4209-4213.

37 a) I. E. Dell'Erba and R. J. J. Williams, Polym. Ing. Sci. 2006, 46, 351-359. b) T. Liu, B. Han, L. Zhang, M. Wu, A. Xing, X. Miao, Y. Meng and X. Li, RSC Adv. 2016, 6, 14211-14221.

38 a) A. Balint, M. Papendick, M. Clauss, C. Müller, F. Giesselmann and S. Naumann, Chem. Commun. 2018, 54, 2220-2223. b) S. Naumann, A. W. Thomas and A. P. Dove, Angew. Chem. Int. Ed. 2015, 54, 9550-9554.

$39 \mathrm{H}$. Morinaga, B. Ochiai and T. Endo, Macromolecules 2007, 40, 6014-6016.

40 D. Chakraborty, A. Rodriguez and E. Y.-X. Chen, Macromolecules 2003, 36, 5470-5481.

41 G.-W. Yang, Y.-Y. Zhang, R. Xie and G.-P. Wu, Angew. Chem. Int. Ed. 2020, 59, 16910-16917.

42 a) J. Raynaud, C. Absalon, Y. Gnanou and D. Taton, J. Am. Chem. Soc. 2009, 131, 3201-3209. b) J. Raynaud, W. N. Ottou, Y. Gnanou and D. Taton, Chem. Commun. 2010, 46, 3203. c) J. Raynaud, C. Absalon, Y. Gnanou and D. Taton, Macromolecules 2010, 43, 2814-2823. d) R. Lindner, M. L. Lejkowski, S. Lavy, P. Deglmann, K. T. Wiss, S. Zarbakhsh, L. Meyer and M. Limbach, ChemCatChem 2014, 6, 618-625.

43 S. Inoue, K. Kitamura and T. Tsuruta, Makromolekular Chem.1969, 69, 250-265.

44 T. Aida and S. Inoue, J. Am. Chem. Soc. 1985, 107, 13581364.

45 Selected examples a) N. J. Van Zee, M. J. Sanford and G. W. Coates, J. Am. Chem. Soc. 2016, 138, 2755-2761; b) A. M. DiCiccio, J. M. Longo, G. G. Rodríguez-Calero and G. W. Coates, J. Am. Chem. Soc. 2016, 138, 7107-7113; c) J. Li, Y. Liu, W.-M. Ren and X.-B. Lu, J. Am. Chem. Soc. 2016, 138, 11493-11496; d) Y. Chen, J. A. Wilson, S. R. Petersen, D. Luong, S. Sallam, J. Mao, C. Wesdemiotis and M. L. Becker, Angew. Chem. Int. Ed. 2018, 57, 12759-12764; e) M. J. Sanford, N. J. Van Zee and G. W. Coates, Chem. Sci. 2018, 9, 134-142; f) J. Martínez, M. Martínez de Sarasa Buchaca, F. de la Cruz-Martínez, C. Alonso-Moreno, L. F. Sánchez-Barba, J. Fernandez-Baeza, A. M. Rodríguez, A. Rodríguez-Diéguez, J. A. Castro-Osma, A. Otero and A. Lara-Sánchez, Dalton Trans. 2018, 47, 7471-7479; g) H.-Y. Ji, B. Wang, L. Pan and Y.-S. Li, Green Chem. 2018, 20, 641-648; h) B. A. Abel, C. A. L. Lidston and G. W. Coates, J. Am. Chem. Soc. 2019, 141, 12760$12769 ;$ i) H. K. Ryu, D. Y. Bae, H. Lim, E. Lee and K.-S. Son, Polym. Chem. 2020, 11, 3756-3761; j) C.-Y. Yu, H.-J. Chuang and B.-T. Ko, Catal. Sci. Technol. 2016, 6, 1779-1791. 
46 B. Han, L. Zhang, B. Liu, X. Dong, I. Kim, Z. Duan and P. Theato, macromolecules 2015, 48, 3431-3437.

47 Z. Hoštálek, O. Trhlíková, Z. Walterová, T. Martinez, F. Peruch, H. Cramail and J. Merna, Eur. Polym. J. 2017, 88, 433447.

48 H.-Y. Ji, X.-L. Chen, B. Wang, L. Pan and Y.-S. Li, Green Chem 2018, 20, 3963-3973.

49 A. Kummari, S. Pappuru, P. K. Gupta, D. Chakraborty and R. S. Verma, Mater. Today Commun. 2019, 19, 306-314.

50 A. Kummari, S. Pappuru and D. Chakraborty, Polym. Chem. 2018, 9, 4052-4062.

51 L. Lin, J. Liang, Y. Xu, S. Wang, M. Xiao, L. Sun and Y. Meng, Green Chem. 2019, 21, 2469-2477.

52 L.-F. Hu, C.-J. Zhang, H.-L. Wu, J.-L. Yang, B. Liu, H.-Y. Duan and X.-H. Zhang, Macromolecules 2018, 51, 3126-3134.

53 J. Zhao, N. Hadjichristidis, H. Schlaad, Polymerization Using Phosphazene Bases, in: N. Hadjichristidis, A. Hirao (Eds.), Anionic Polymerization: Principles, Practice, Strength, Consequences and Applications, Springer Japan, Tokyo, 2015: pp. 429-449.

54 H. Li, J. Zhao and G. Zhang, ACS Macro Lett. 2017, 6, 10941098.

55 H. Li, H. Luo, J. Zhao and G. Zhang, Macromolecules 2018, 51, 2247-2257.

56 X. Kou, Y. Li, Y. Shen and Z. Li, Macromol. Chem. Phys. 2019, 220, 1900416.

57 J. Zhang, L. Wang, S. Liu and Z. Li, J. Polym. Sci. 2020, 58, 803810.

58 L.-F. Hu, D.-J. Chen, J.-L. Yang and X.-H. Zhang, Molecules 2020, 25, 253.

59 a) H.-Y. Ji, D.-P. Song, B. Wang, L. Pan and Y.-S. Li, Green Chem. 2019, 21, 6123-6132; b) S. Zhu, Y. Wang, W. Ding, X. Zhou, Y. Liao and X. Xie, Polym. Chem. 2020, 11, 1691-1695 c) H.-Y. Ji, B. Wang, L. Pan and Y.-S. Li, Angew. Chem. Int. Ed. 2018, 57, 16888-1689.

60 J. C. Worch, H. Prydderch, S. Jimaja, P. Bexis, M. L. Becker and A. P. Dove, Nat. Chem. Rev. 2019, 3, 514-535.

61 J. M. Longo, A. M. DiCiccio and G. W. Coates, J. Am. Chem. Soc. 2014, 136, 15897-15900.

62 J. Li, B.-H. Ren, S.-Y. Chen, G.-H. He, Y. Liu, W.-M. Ren, H. Zhou and X.-B. Lu, ACS Catal. 2019, 9, 1915-1922.

63 J. Li, B.-H. Ren, Z.-Q. Wan, S.-Y. Chen, Y. Liu, W.-M. Ren and X.-B. Lu, J. Am. Chem. Soc. 2019, 141, 8937-8942.

64 a) M. Alves, B. Grignard, R. Mereau, C. Jerome, T. Tassaing and C. Detrembleur, Catal. Sci. Technol. 2017, 7, 2651-2684. b) P.-A. Wang, Beil. J. Org. Chem. 2013, 9, 1677-1695.

65 M. Rabnawaz, I. Wyman, R. Auras and S. Cheng, Green Chem. 2017, 19, 4737-4753.

66 X. Zhang, M. Fèvre, G. O. Jones and R. M. Waymouth, Chem. Rev. 2018, 118, 839-885. 